\title{
الاقتصاد الإسلامي: حفرية مصطلح
}

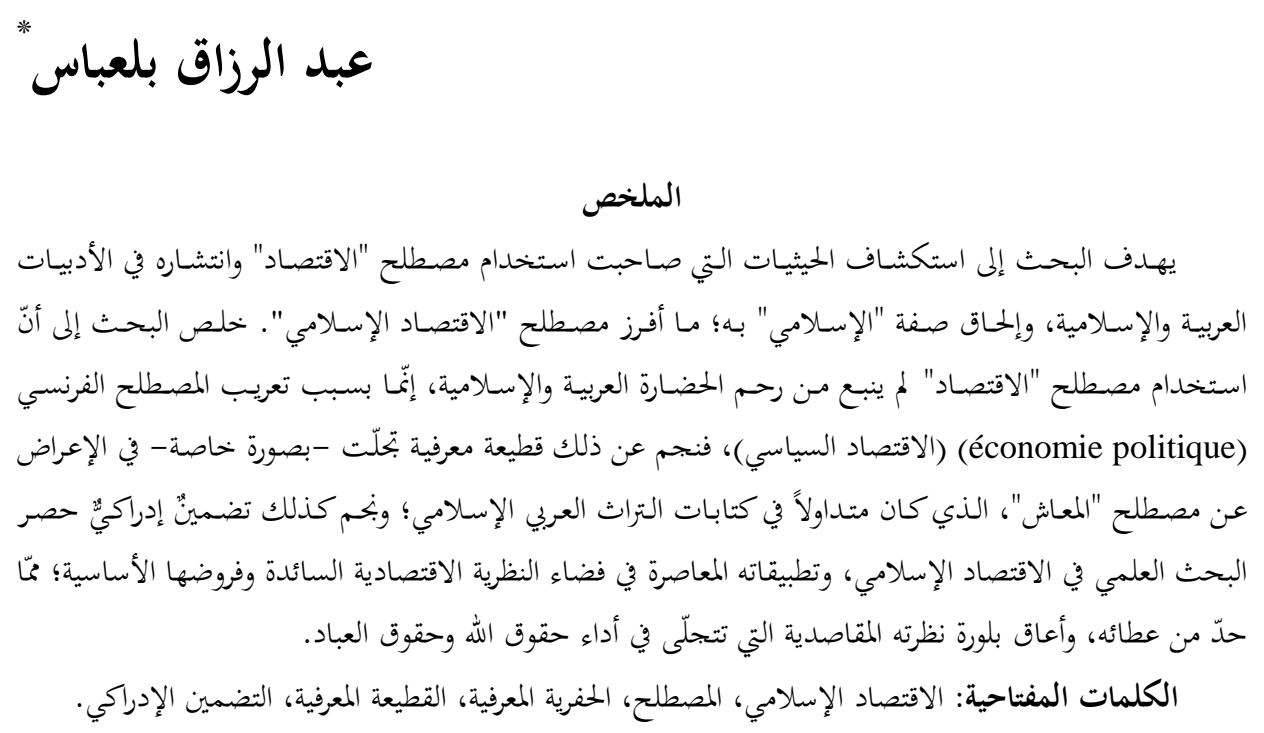

\section{Islamic Economics: Archaeology of a Concept}

\begin{abstract}
The purpose of this study is to explore the conditions that accompanied the use and dissemination of the concept of economics in Arabic and Islamic literature and its junction with the adjective «Islamic», which has led to the concept of «Islamic economics». The study concludes that the adoption of the concept of economics has not been generated by Arabic and Islamic civilizational matrix, but rather the translation of the French concept of «économie politique». This led, on the one hand, to an epistemological break that gradually substituted the concept of economics to «ma'ach» adopted by the Arabic and Islamic heritage, and, on the other hand, to embed the Islamic economic research and its contemporary applications in the mainstream economic thinking and its hypotheses; which has limited its perspective and constrained its teleological vision characterized by the fulfillment of the rights of God and those of the humans.
\end{abstract}

Keywords: Islamic Economics, concept, archeology of knowledge, epistemological break, cognitive embeddedness.

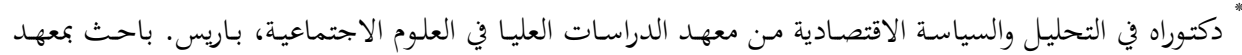

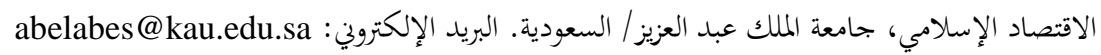

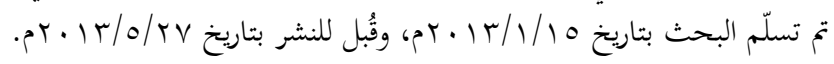


في سـياق الحسوار المفتـوح حـول مستتقبل الاقتصـاد الإسـلامي، الـذي أطلقـه معهد

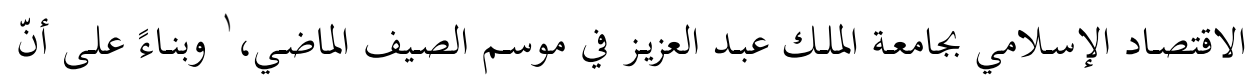

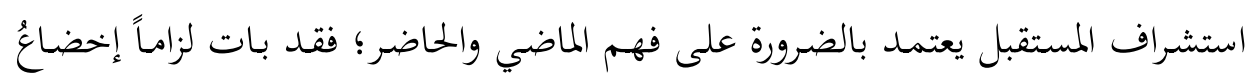

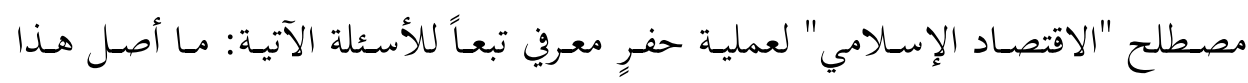
المصطلح؟ وكيف وصل إلينا؟ وإلى أين يقودنا؟

فإذا كان واضع المصطلح نفسه لم يكن يتوقع أن يشيع استخدامه على نطاق واسع

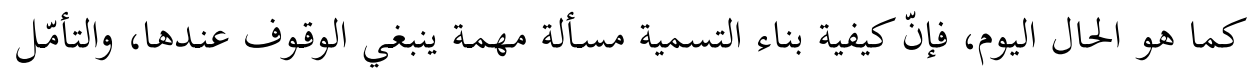
فيها بتجرّد وموضوعية. وقد اختلف الباحثون في تحديد تاريخ ظهور مصطلح باحل "الاقتصاد

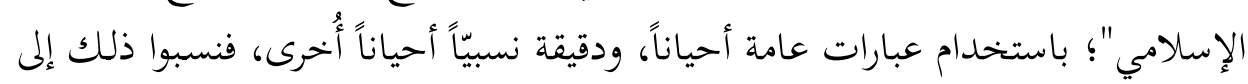

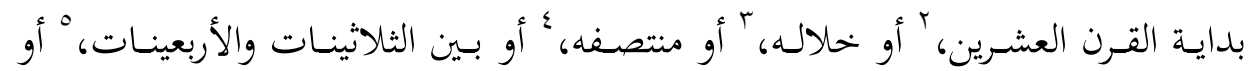

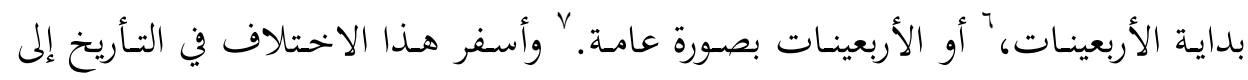

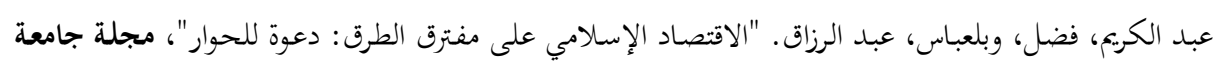

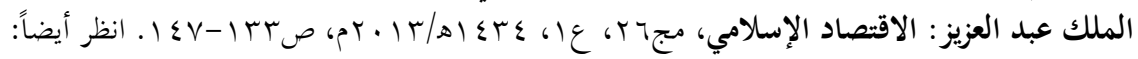

- Al-Bashir, Fadul Abdul Karim and Abderrazak Said Belabes. Islamic Economics at Crossroads: A Call for Discussion, Journal of King Abdulaziz University: Islamic Economics, Vol. 26, No. 1, 2013, p.289-301.

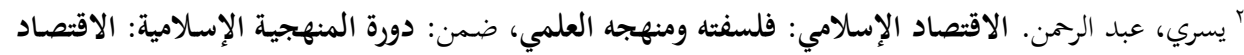

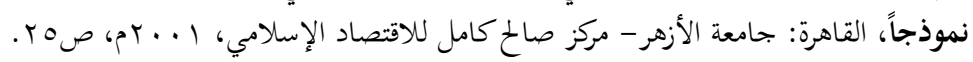

${ }^{3}$ Feillard, Gwenël. Insuffler l'esprit du capitalisme à l'Umma: la formation d'une "éthique islamique du travail" en Indonésie, Critique Internationale, n²5, Octobre 2004, p.93.

؛ العوضي، رفعت. الاقتصاد الإسلامي: دلالة المصطلح، موقع الرابطة العالمية لخريجي الأزهر، 9 . . بم.

${ }^{5}$ Salleh, Muhammed Syukri. Islamic Economics Revisited: Re-Contemplating Unresolved and Assumptions, 8th International Conference on Islamic Economics and Finance, Doha, 2011, note 2, p.1.

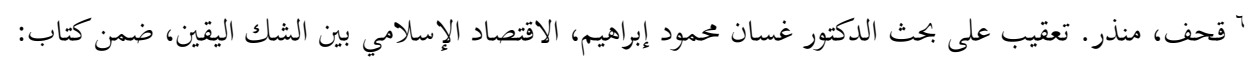

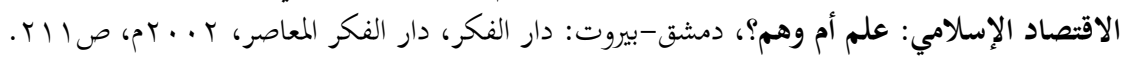

${ }^{7}$ Kuran, Timur. Islam and Mammon: The Economic Predicaments of Islamism, Princeton: Princeton University Press, 2004, p.58. 
تباينٍ في تحديد مَنْ كان له قصب السبق والريادة في استخدام المصطلح وإطلاقه، وهي مسألة يشوبها عدم الدقة في كثير من الأحيان. ^

يقف الباحثون من حيث الوضعية المعرفية بشأن نشأة مصطلح الاقتصاد الإسلامي

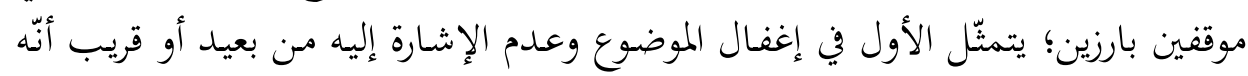

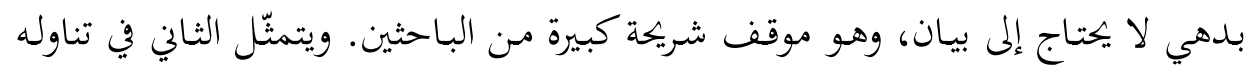

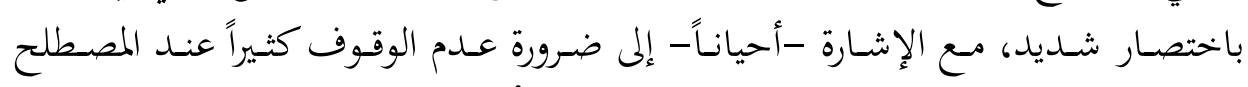

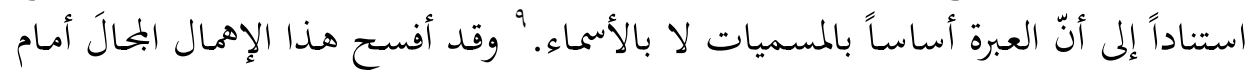

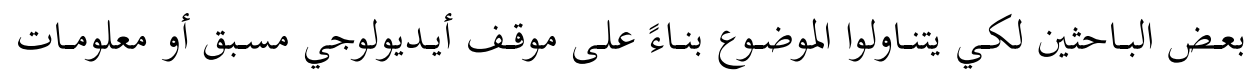

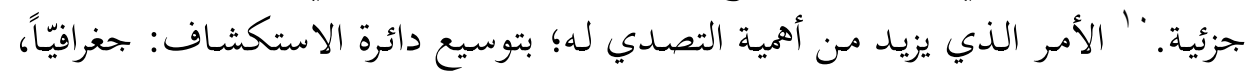

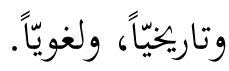

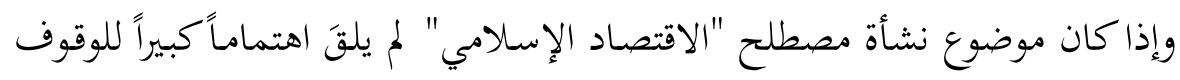

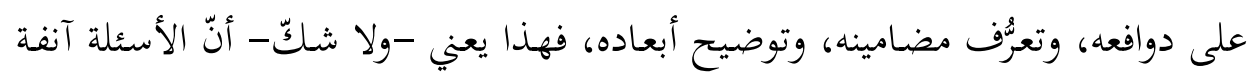

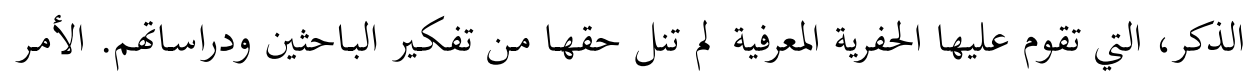

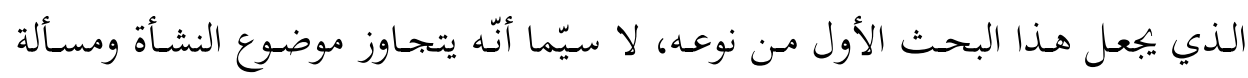

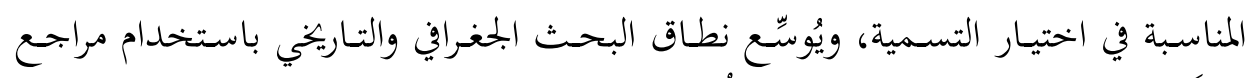

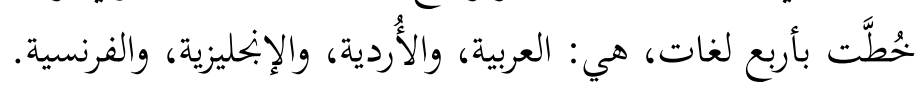

وبمـا أنّ المصطلح مُركَّب مـن كلمـة أساسية هي "الاقتصـاد"، ومـن صفة تابعة هي

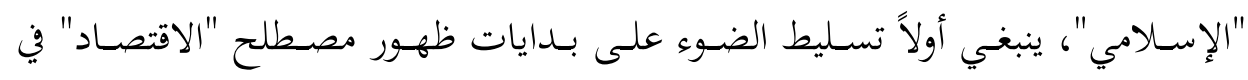

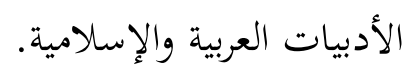

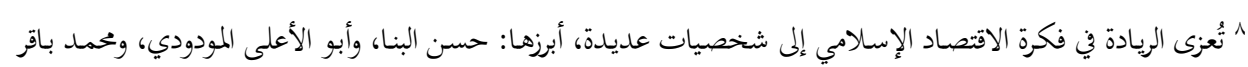

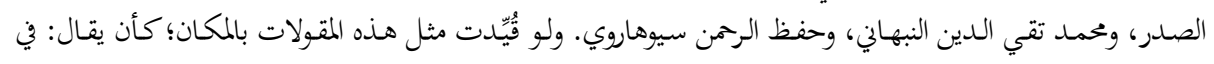

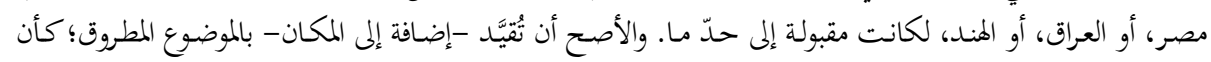

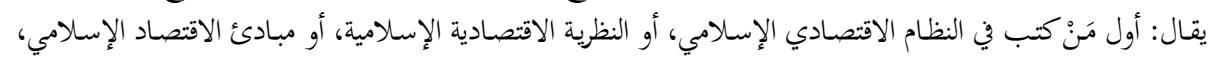

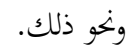
9 دوابة، أشرف. هل يوجد شيء اسمه الاقتصاد الإسلامي؟، م.ن، المركز العربي للدراسات والأبحاث، 1 أبريل ${ }^{10}$ Kuran, Timur. The genesis of Islamic economics: A chapter in the politics of Muslim, Social Research, 1997, 64(2), p.281-338. 


\section{أولاً: نشأة مصطلح "الاقتصاد" في الأدبيات العربية والإسلامية}

استُحِدِت كلمة "الاقتصاد" في الأدبيات العربية والإسلامية طوال قرون عدّة بمعناهـا

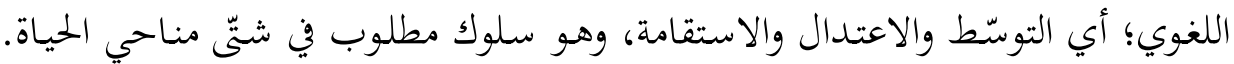

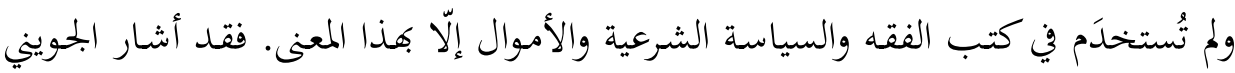

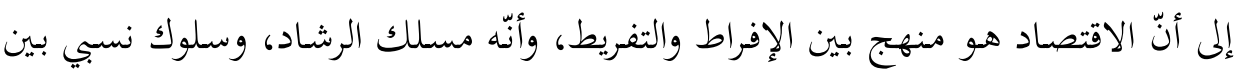

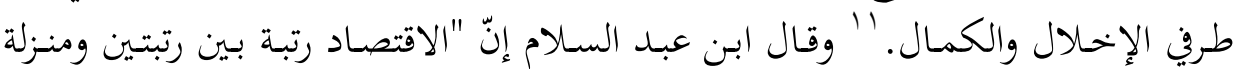

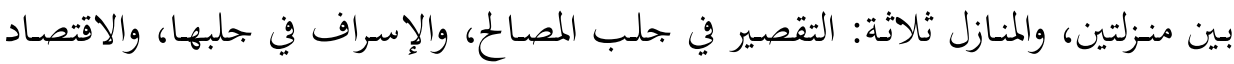

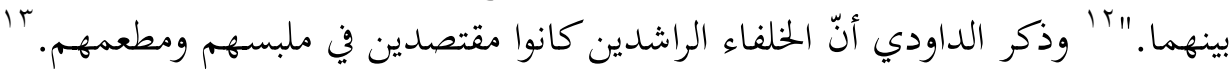

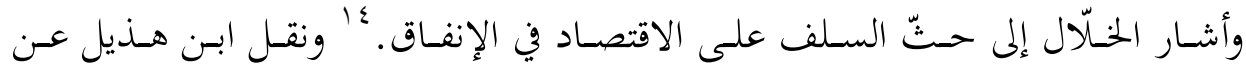

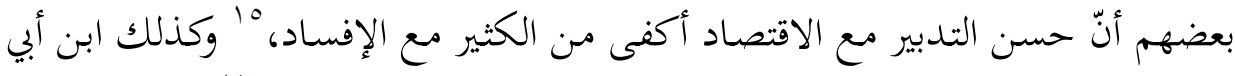

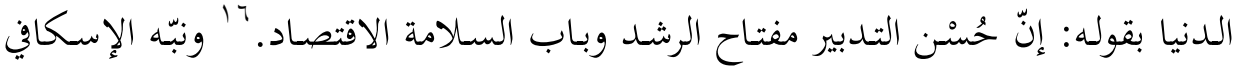

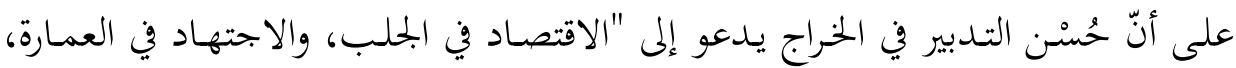

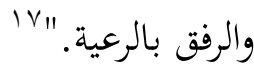

وهكـذا لم تُسـتحدَم كلمـة "الاقتصـاد" بـالمعنى الاصـطلاحي الشـائع في الأدبيـات

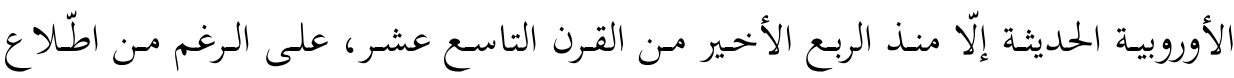

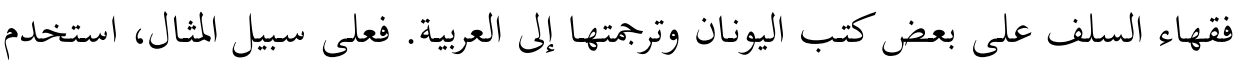

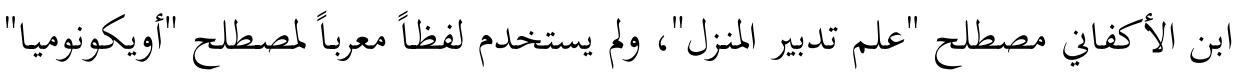
(oíkovopía)

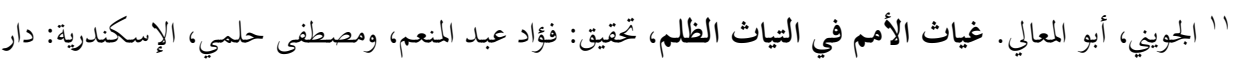

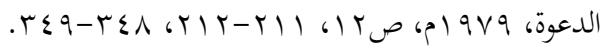

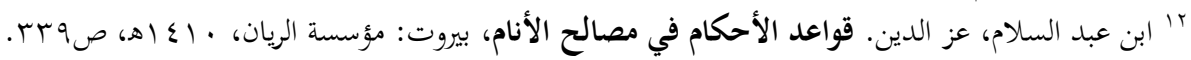

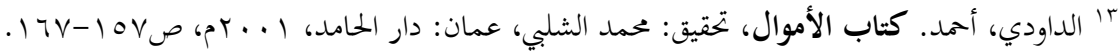

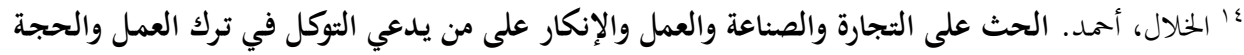

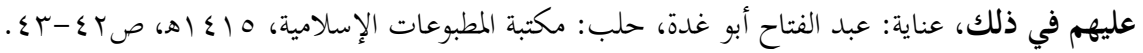

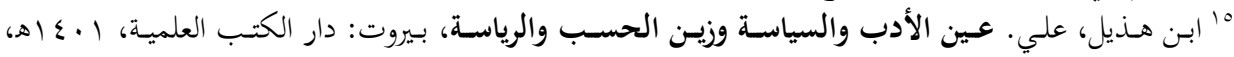

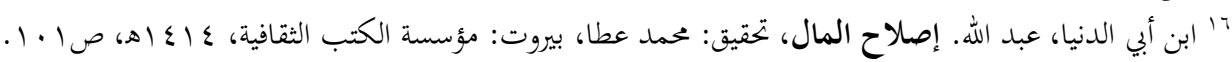

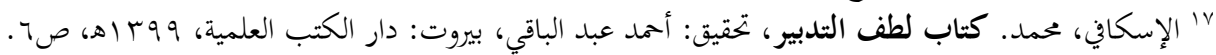

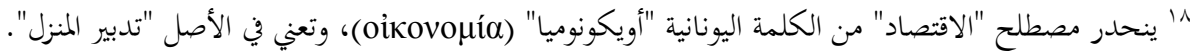




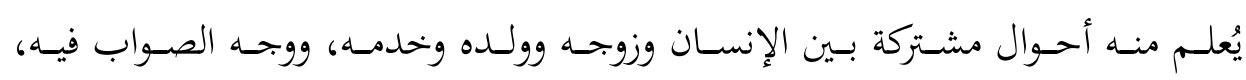

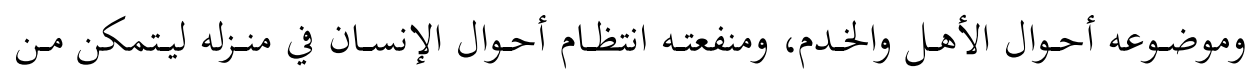

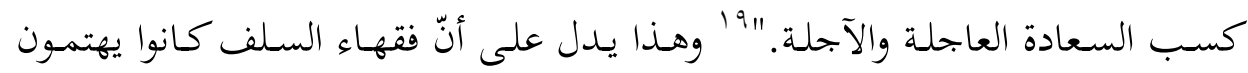

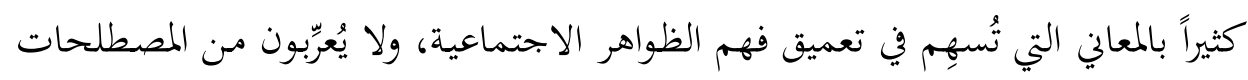

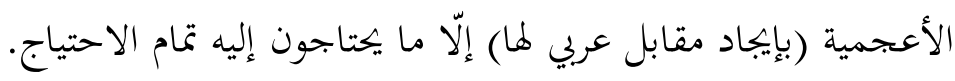

ولعلّ أول مَنْ أدخل مصطلح "الاقتصاد" في الأدبيات العربية هو خليل أفندي، في

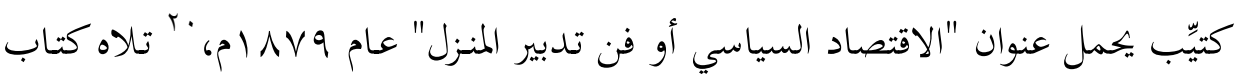

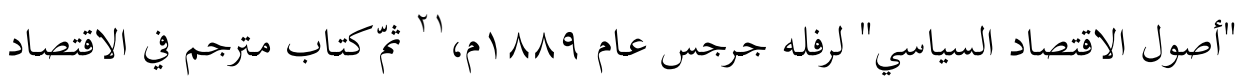

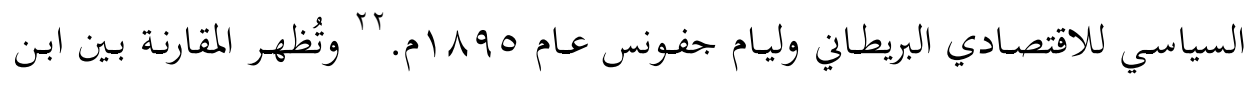

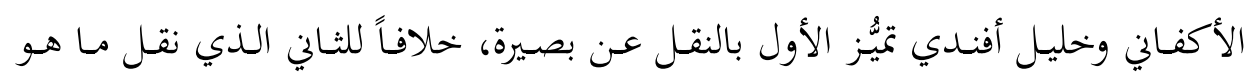

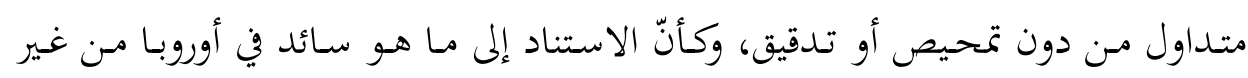
تمحيص والبناء عليه حتمية لا يمكن العدول عنها. وفي مطلع القرن العشرين بَّ ظهر كتاب دراسي في الاقتصاد السياسي باللغة الأردية، عنوانه "علم الاقتصـاد جـس كا معروف نـام علم سياست مـدن حي" (علم الاقتصـاد

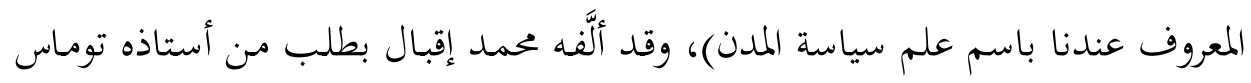

919 ابن الأكفاني، محمد. كتاب إرشاد القاصد إلى أسنى المقاصد، موسوعة موجزة في العلوم العربية الإسلامية،

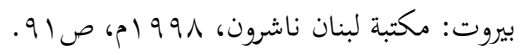

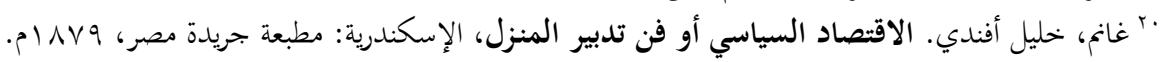

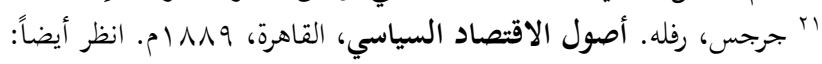

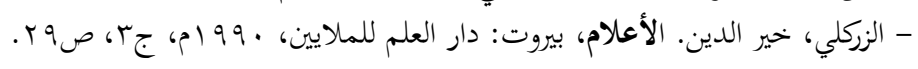

${ }^{22}$ Jevons, William Stanley. The Theory of Political Economy, London: Macmillan, 1871.

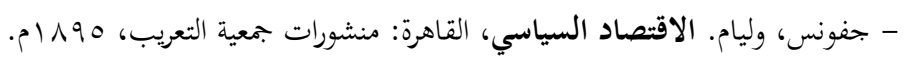

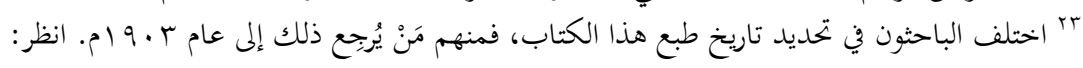
- Mir, Mustansir. Iqbal: Makers of Islamic Civilization, London - New York: I.B.Tauris \& Co Ltd and Oxford University Press India, 2007, p.19.

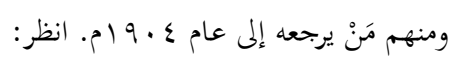

- Tahir, Pervez. Introducing Iqbal the Economist, The Pakistan Development Review, 40: 4, Winter 2001, p.1176. 
أرنولد (Thomas Arnold)، وكذلك الكتاب الموسوم بِّ"المرصاد في مسائل الاقتصاد"،

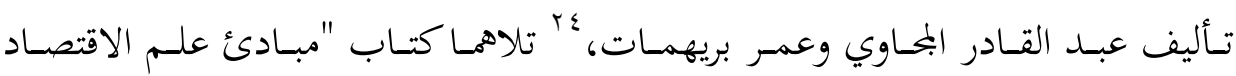

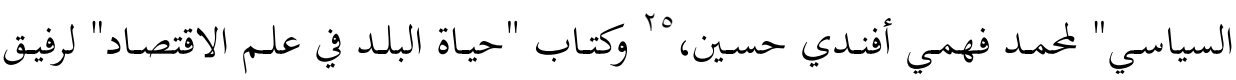

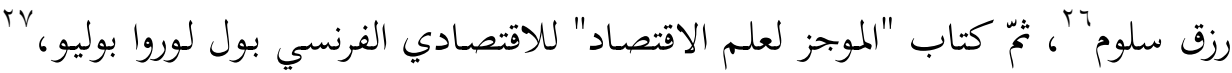

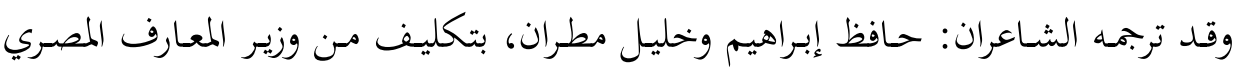

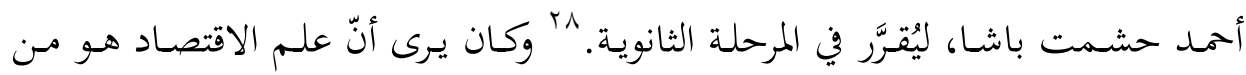

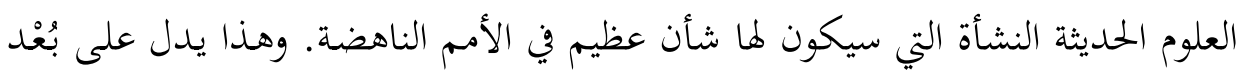

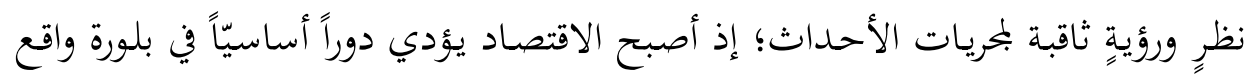

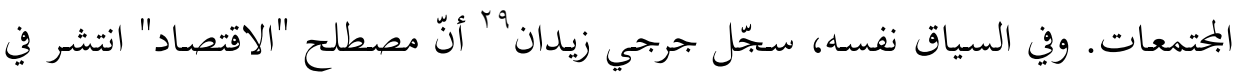

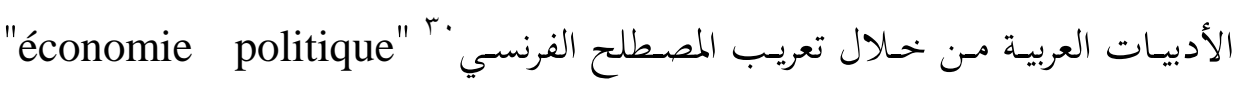

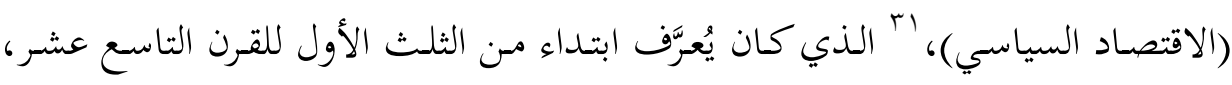

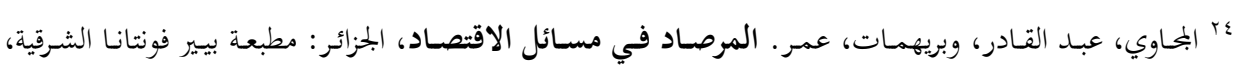
. $19 \cdot \varepsilon$ هـ حسين، محمد فهمي أفندي. مبادئ علم الاقتصاد السياسي، القاهرة: مطبعة السعادة، نُشِر الجزء الأول منه عام

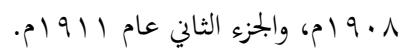

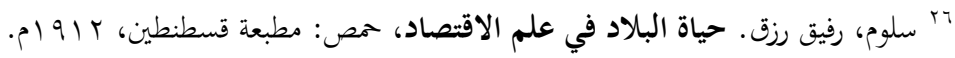
27 Leroy-Beaulieu, Paul. Précis d'économie politique, Paris: Librairie Charles Delagrave, 1888, http://gallica.bnf.fr/ark:/12148/bpt6k112933x

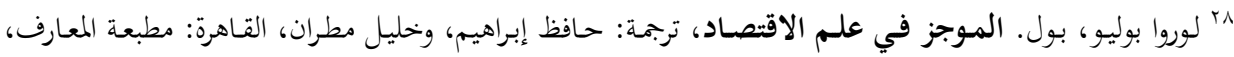

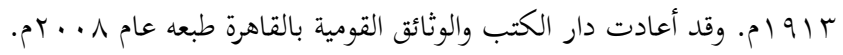

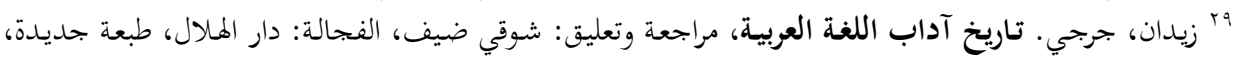

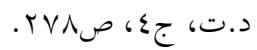

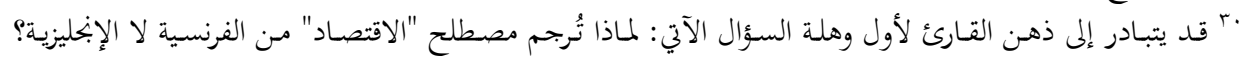

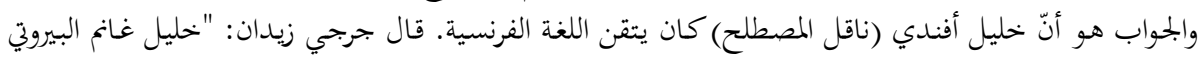

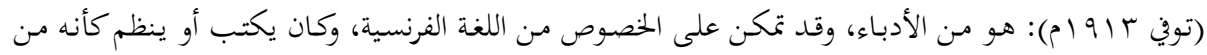
أهلها". انظر: (نوان

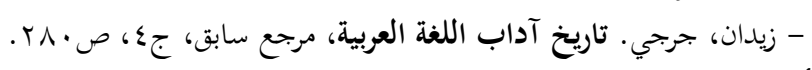

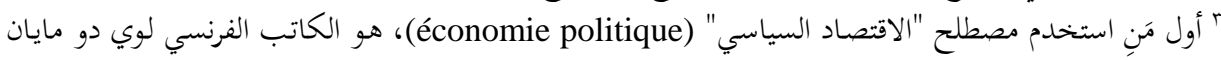

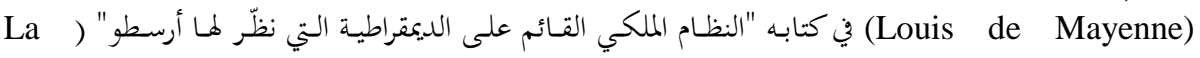
لكonarchie aristodémocratique

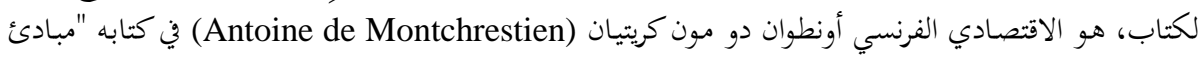


وَفقق قـاموس الأكاديميـة الفرنسـية، بأنّهـ "العــم الـذي يتنـاول إيبـاد الثروات وتوزيعها

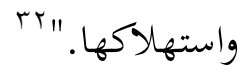

أحسدث تـاول مصطلح "الاقتصـاد" بنـاءً على تعريب المصطلح الأعجمي قطيعةً

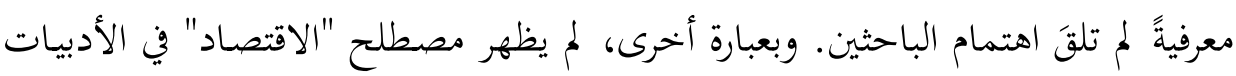

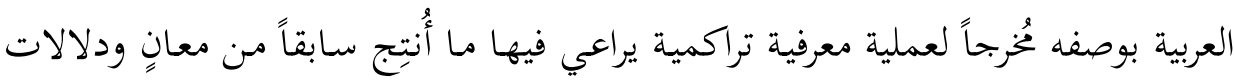

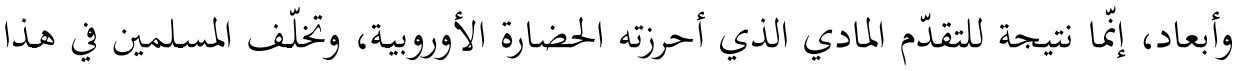

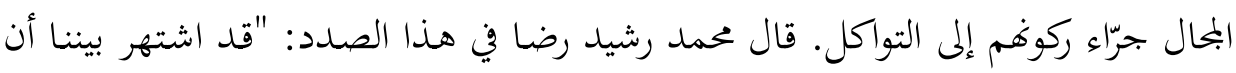

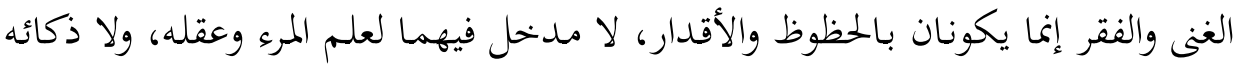

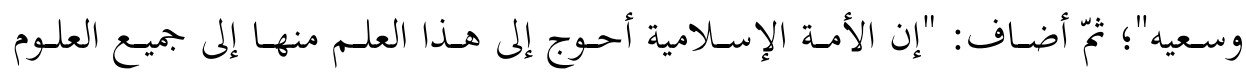

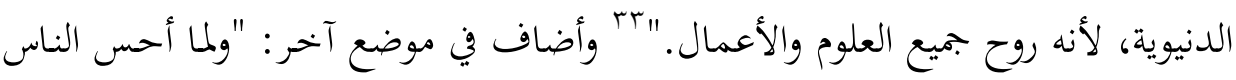

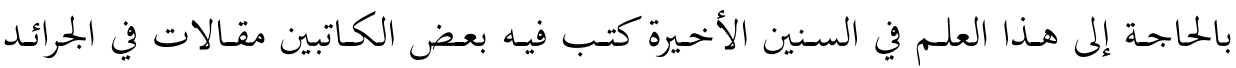

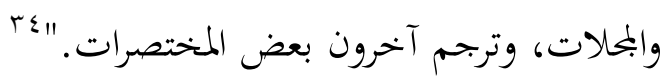

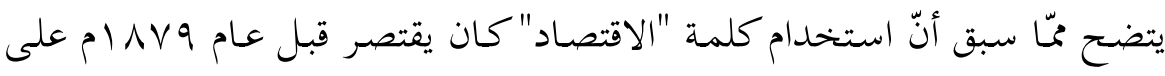

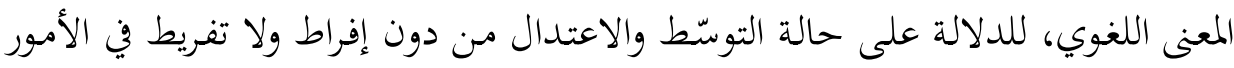

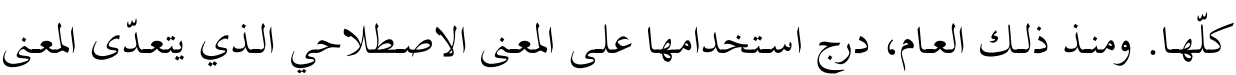

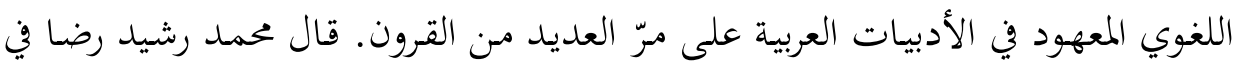

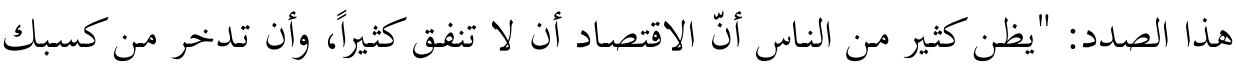

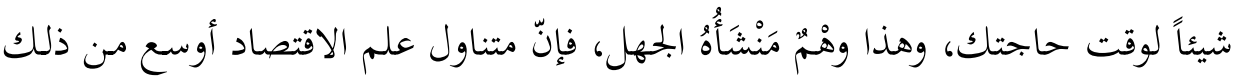

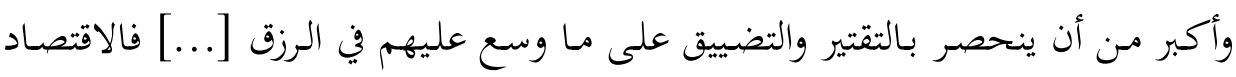

الاقتصاد السياسي" (Traité de l'économie politique)، المنشور بباريس عام 17 إم وبناءً على ترجمته، ظهر المصطلح الإنليزي (political economy).

${ }^{32}$ Académie française. Dictionnaire de l'Académie française, Paris: Editions de l'Académie française, 6 é édition, 1835, http://portail.atilf.fr/

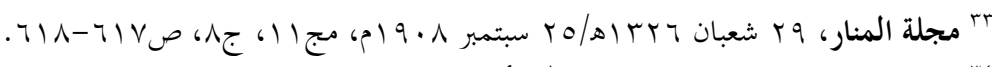

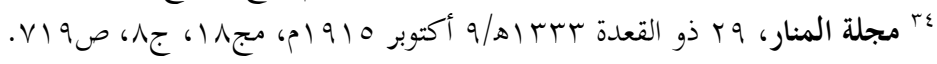


هو ما يُوجِد ثروة الأمة والفرد ويُنميها، أي أن تعلم كيفية كسب المال، وكيفية إنفاقه بما

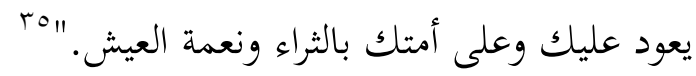

والحـديث عن تراث الاقتصاد الإسـلامي أو الفكر الاقتصادي الإسـلامي قبل هذه

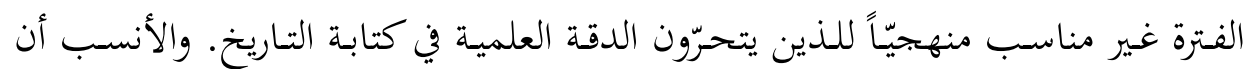

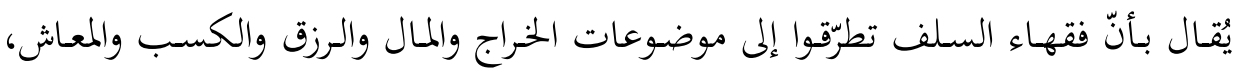

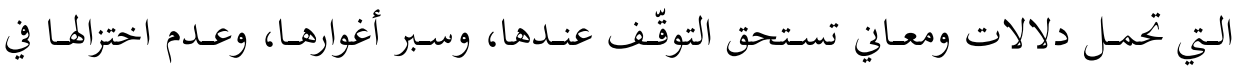

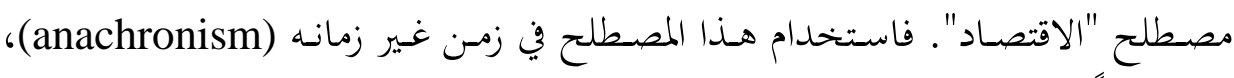

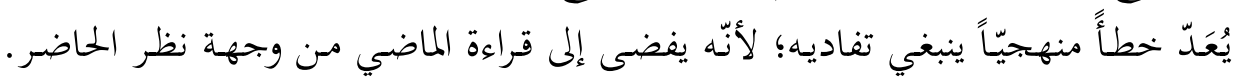

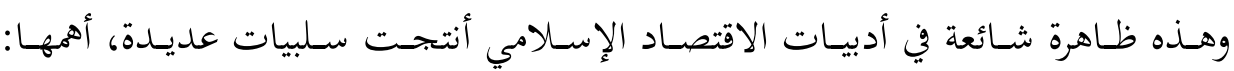

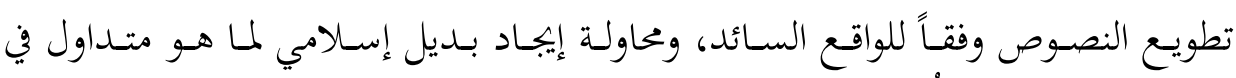

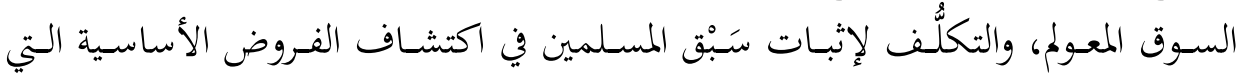
أفرزتا المدرسة النيوكلاسيكية، مثل الندرة والرشد وتعظيم الربح، بل حتى أحياناً في الأمثلة

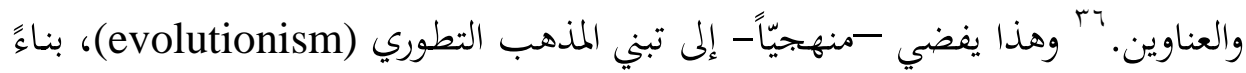

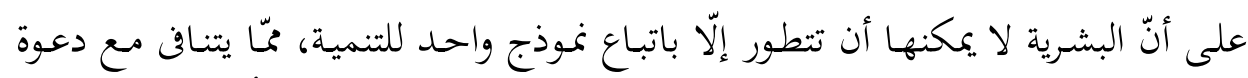

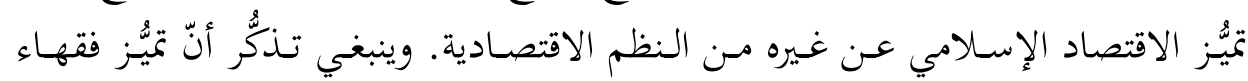

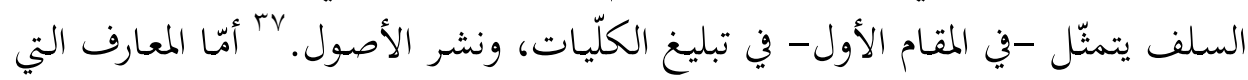

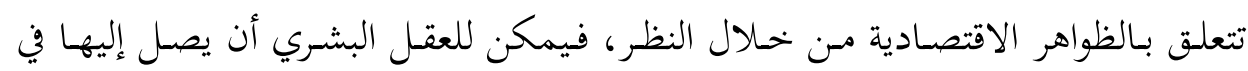

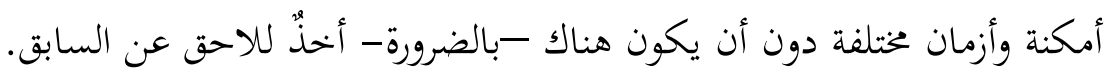

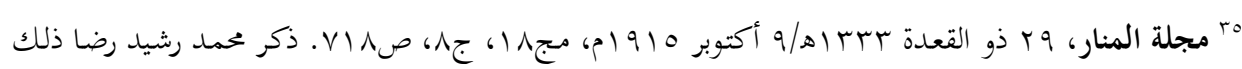

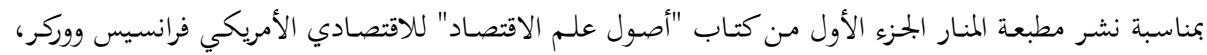

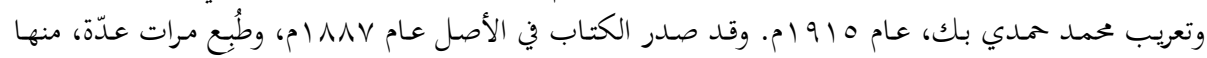

الطبعة الآتية:

- Walker, Francis Amassa. Political Economy, London: Macmillan, 1892.

بr كافتراض أنّ آدم سميث اقتبس من أبي حامد الغزالي مثال الدبوس، ومن الجويني عنوان كتابه "غياث الأمم" ليصير

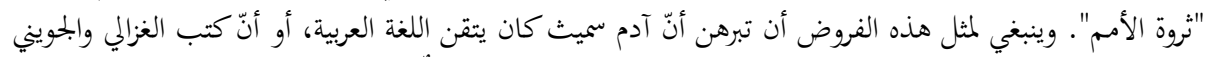

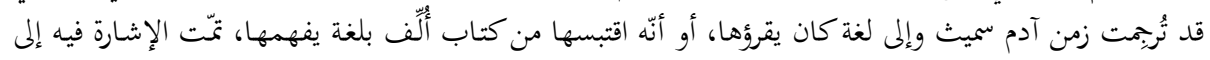
مثال الغزالي، أو عنوان الجويني، أو الاثنين معاً.

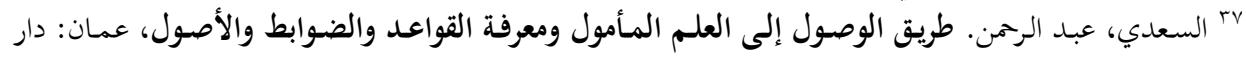


ثانياً: استخدام علماء الاصلاح مصطلح "الاقتصاد" من دون المصدر "الإسلامي" تطرّق بعض علماء الإصلاح الاجتماعي من المسلمين إلى موضوع الاقتصاد من دون

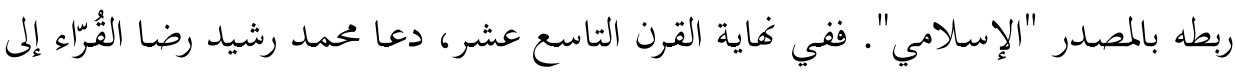

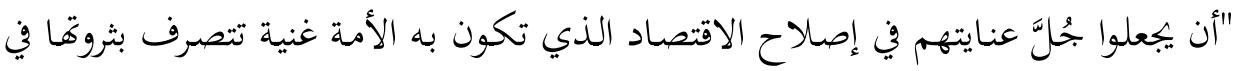

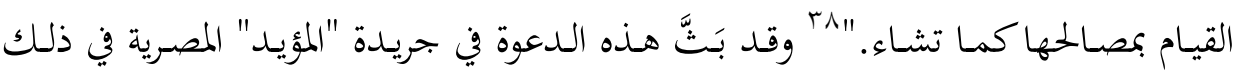

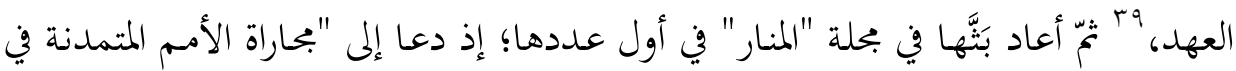

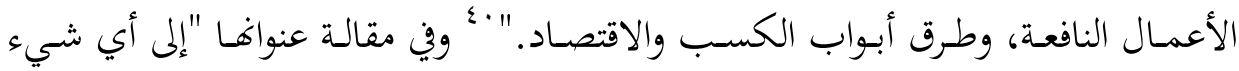

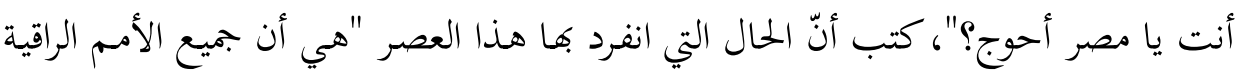

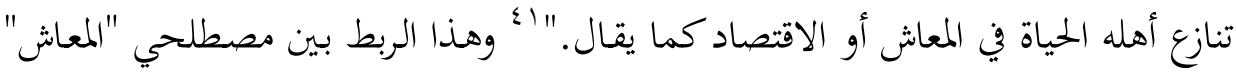

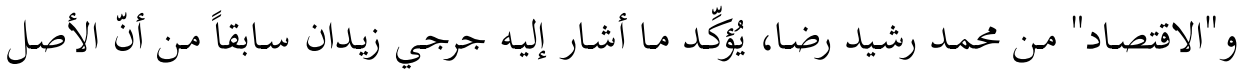

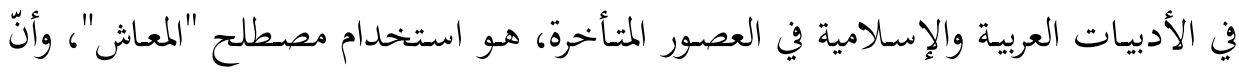

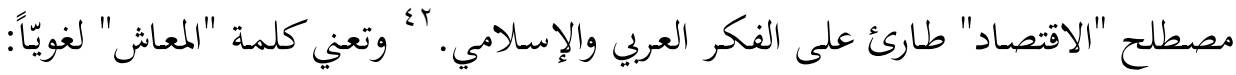

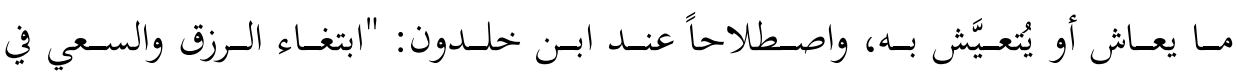
تحصيله." "خعموضوع المعاش بمعنى أعم، هو: الأصول المادية للحياة.

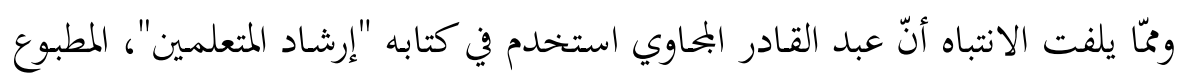

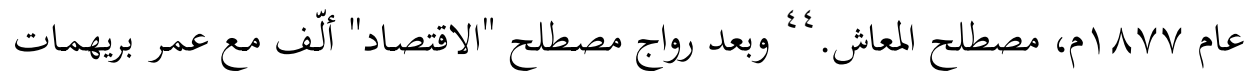

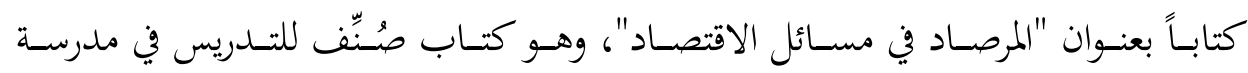

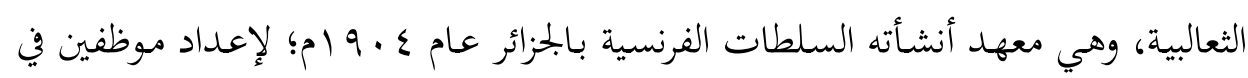

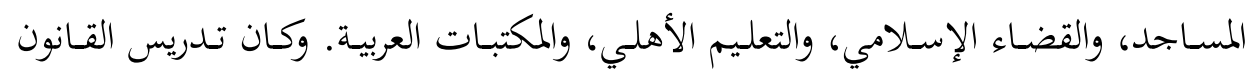

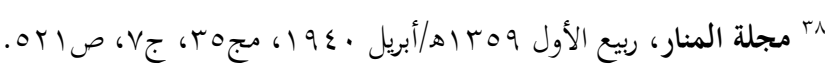

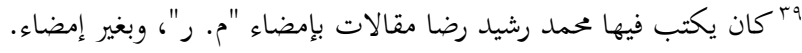

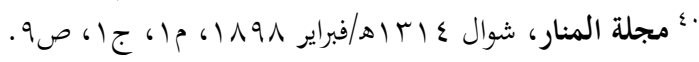

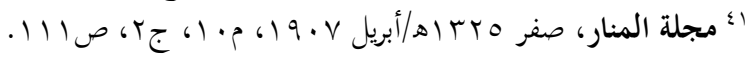

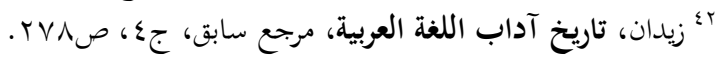

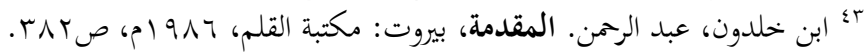

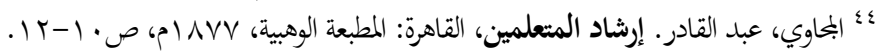


يضم -آنذاك- القانون المدني، والقانون الإداري، والاقتصاد السياسي. هـ وجاء في مقدّمته: "وبعد، فإنه لما دلّت الآيات القرآنية والأحاديث الشريفة النبوية على أن الله خلق هذا العالم للعمـارة، وهـي تتوقـف على تنظيمـات اقتصـادية وافـرة، وقـوانين يُصــار إليهـا في المعيشـة الدنيوية، وكان هـا العلم مُفرّقاً في بطون الكتب والدواوين السـيّة، فصعب لأجل ذلك الاطلالع على قواعـده، واقتطاف أزهـاره وفوائده، ظهر لنـا أن بجمـع تلـك القواعـد لتكـون

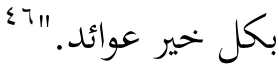

وهذا يتضح أنّ مصطلح "الاقتصاد" استُخدِم في الأدبيات العربية والإسالامية منذ

هاية القرن التاسع عشر الميلادي من دون أن يُربط بصفة "الإسالامي" لينتشر بعد ذلك تدريجيّاً بين العلماء والأدباء والقائمين على الصحف ذات التوجّه الإصالاحي الإسالامي. فـدعا عبـد الرحمن بن عمـر في مقالة عنواهـا "الاقتصـاد" نُشِـرت عـام جب 9 ام إلى دراسـة علم الاقتصـاد والتوسّع فيـ؛ "لأن حيـاة كل أمـة منوطة بكيـاة حركتها الاقتصـادية ومماتها

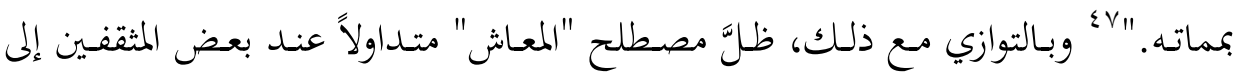
بداية العشرينيات كما يظهر في مقالة لعبد الحفيظ الهـاشي بعنوان "الأزمـة المعاشية. "^؛ فالأصـل منــ دخـول مصسطلح "الاقتصـاد" في الأدبيـات الإسـلامية، هـو استخدام هـذا المصطلح، لا مصطلح "الاقتصاد الإسـالامي "كما هـو شائع اليوم! وهـذه مسألة دقيقة لم يتنبّه لما الباحثون حتى الآن.

\section{ثالثاً: ظهور مصطلح "الاقتصاد الإسلامي"}

مـن الأحـداث العلميـة التي مهّدات الطريـق لنشـأة مصـطلح "الاقتصـاد الإسـلامي" ظهـور سلسـلة مــن المقـالات الـتي أخـذت على عاتقهـا تسـليط الضـوء على الفكـر الاقتصـادي لبعض الفقهاء والفلاسفة مـن العرب والمسـلمسن. ففي عـام ب ا و ام، نشر

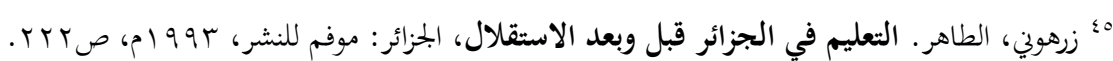

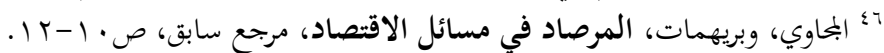

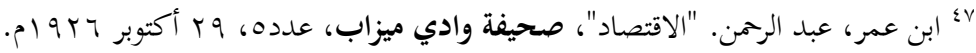

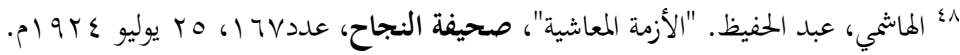


الاقتصـادي الفرنسـي روين مـونيي مقالـة علميـة تنـاول فيهـا الأفكـار الاقتصـادية لابــن

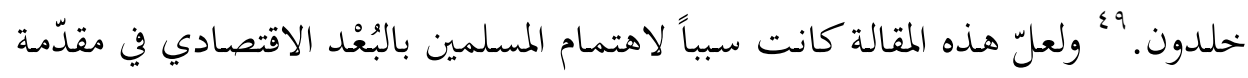

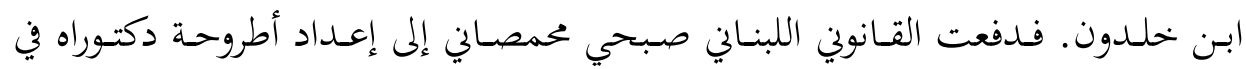
جامعة ليون الفرنسية بعنوان "الأفكار الاقتصـادية لابن خلمدون: دراسـة تاريخيـة تحليليـة

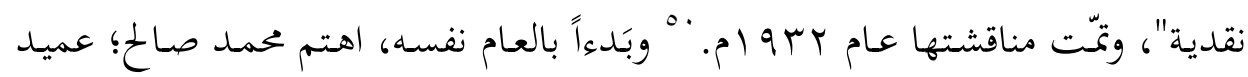
كلية الحقوق بجامعة القاهرة سابقاً -عبر سلسلة من المقالات- بالفكر الاقتصادي العربي في القـرن الخـامس عشـر؛ بتنـاول آراء ابـن خلـدون والمقريـزي والـدُّلجي. اه وعلمى المنسوال

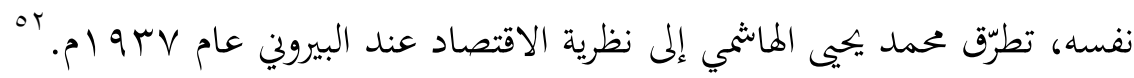

وفي السابع من شهر يونيو عام 9 ب 9 (م، نوقشت أطروحة دكتوراه في جامعة باريس،

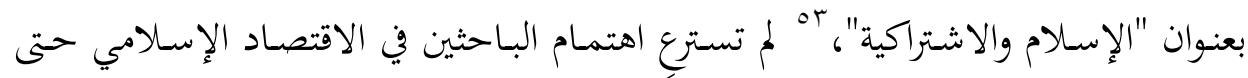

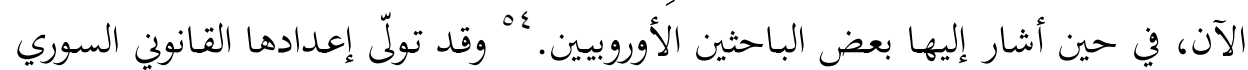

${ }^{49}$ Maunier, René. Les Idées économiques d'un philosophe arabe, Ibn Khaldoun, Revue d'histoire économique et sociale, Paris, 1912, p.409-419.

50 Mahmassani, Sobhi. Les idées économiques d'Ibn Khaldoun: essai historique, analytique et critique, thèse en droit, Université de Lyon, 1932.

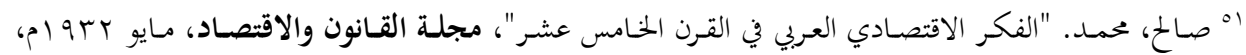

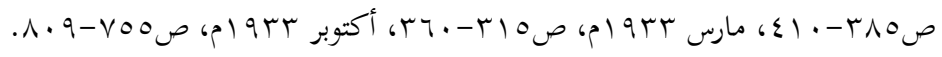

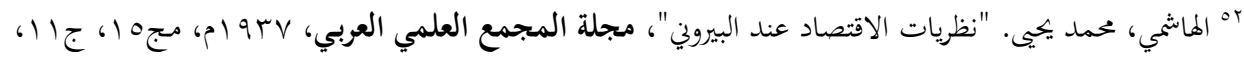

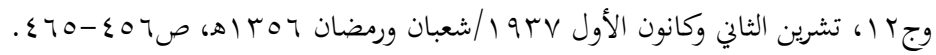

${ }^{53}$ Barazi, Mouhssine. Islamisme et socialisme, thèse de doctorat, faculté de droit et des sciences économiques, université de Paris (1896-1968), présentée et soutenue le 7 juin 1929, publiée par la Librairie Orientaliste Paul Geuthner la même année.

${ }^{54}$ D.S.M. Islamisme et socialisme par Mouhssine Barazi, 1929, Journal of the Royal Asiatic Society, Vol. 64, Issue 01, January 1932, p.151-152; Wallacher, Johannes, Reder, Michael, \& Karcher, Tobias. Unternehmensethik im Spannungsfeld der Kulturen und Religionen, Stuttgart: W. Kohlhammer Verlag, 2006, p.53-54; Martin, Richard \& Barzegar, Abbas. Islamism: Contested Perspectives on Political Islam, Stanford: Stanford University Press, 2009, p.158; Ende, Werner \& Steinbach, Udo. Islam in the World Today: A Handbook of Politics, Religion, Culture, and Society, Ithaca: Cornell University Press, 2010, p.131. 
حسن البرازي، وكانت سوريا -آنذاك - خاضعة للانتداب الفرنسي. ومـن أهـم مـا تميَّزت به هذه الأطروحة، التطرّق -أول مرة في بحث أكاديمي - إلى العلاقة بين الإسلام والاشتراكية، والاستنتاج بأنب الاشتراكية -بنفيها الملكية الفردية- تتعارض مع قواعد الفقه الإسالامي6،

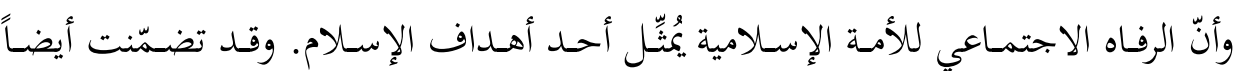
البذور الأولى لما أصبح يُعرف لاحقاً بِّ"النظرية الاقتصادية في الإسلام" أه وهي تُصنَّف عادة

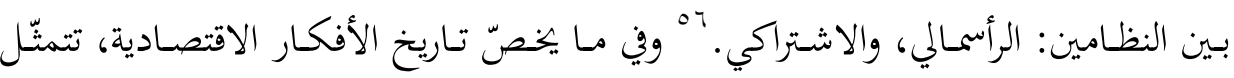
أهميـة الأطروحـة في إنكارهـا الاستشهاد بالنصوص الشـعية، أو بوقائع مـن تاريخـه لتبرير مـا يُسمّى بالاشتراكية الإسلامية.

ظهر مصطلح "الاقتصساد الإسـلامي" أول مرة -بنـاءً على مـا توفر من مصادر حتى

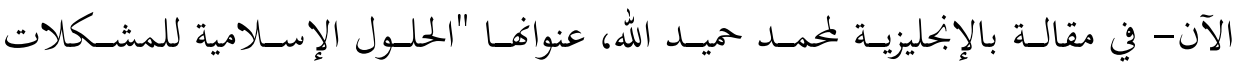

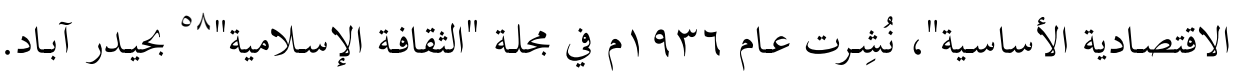
وهذا يُبيِّن أنّ مصطلح "الاقتصاد الإسالامي" انبثق عن اجتهاد فردي، لا من وضع أحد بحـامع اللغـة العربيـة، وذلك بعـد التـلـقيق في إيجابيات استخدام هـذا المصطلح وسـلبياته. وكـان محمـد حميـد الله قـد ذكـر المصـطلح بعـد أشـهر مـن مناقشتـه أطروحـة الـدكتوراه في

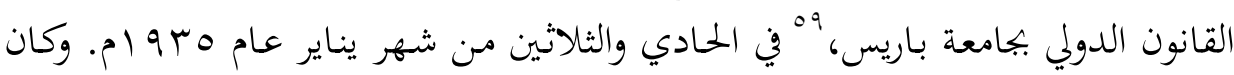
الاقتصاد السياسي يُـرَّس -آنذاك - كمادة إجبارية في كليات القانون الفرنسية منذ عام

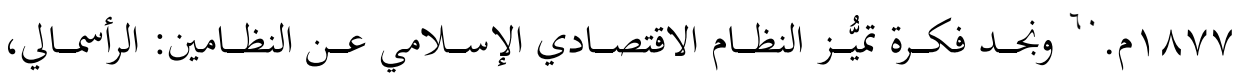
${ }^{55}$ D.S.M. op. cit, p. 151.

${ }^{56}$ Ende, Werner \& Steinbach, Udo, op. cit.; Ende, Werner \& Steinbach, Udo, op. cit.

${ }^{57}$ Ende, Werner \& Steinbach, Udo, op. cit.

${ }^{58}$ Hamidullah, Muhammad. Islam's solution of the basic economic problems: the position of labor, Islamic culture (Hyderabad Deccan), Vol. 10, No. 2, April 1936, p.213-233.

${ }^{59}$ Hamidullah, Muhammad. Documents sur la diplomatie musulmane à l'époque du Prophète et des khalifes orthodoxes, préface de Maurice Gaudefroy-Demombynes, Université de Paris (1896-1968), faculté des lettres, thèse de doctorat d'Université, Paris: G.-P. Maisonneuve, 1935.

${ }^{60}$ Van Lemesle, Lucette. L'économie politique à la conquête d'une légitimité 18961937, Actes de recherches en sciences sociales, vol. 47-48, juin 1983, p.113. 


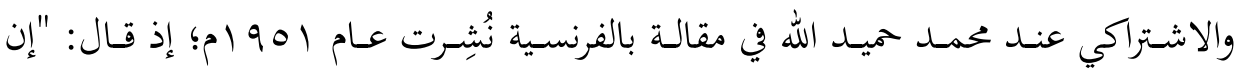

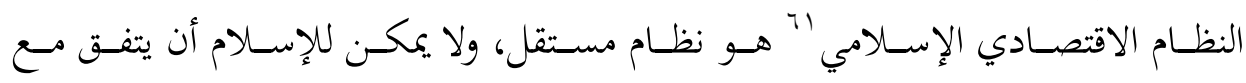

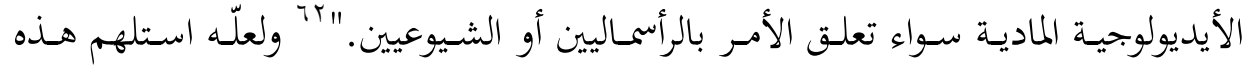

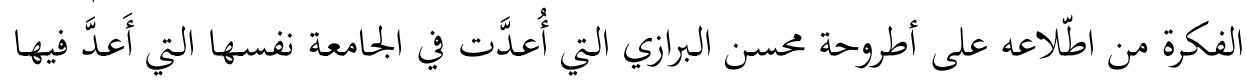

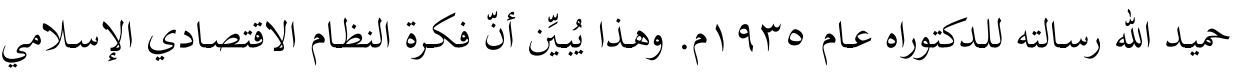

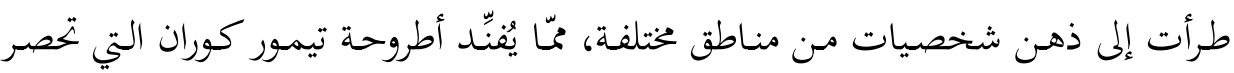

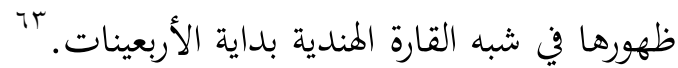

بناءً على ما سبق، وبالإضافة إلى الرصد الببليوغرافي بلغات عديدة (الملحق)، يتضح

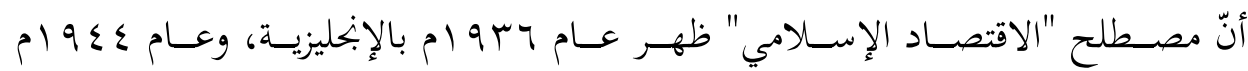

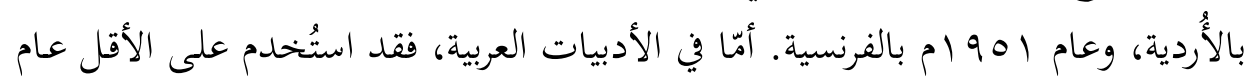

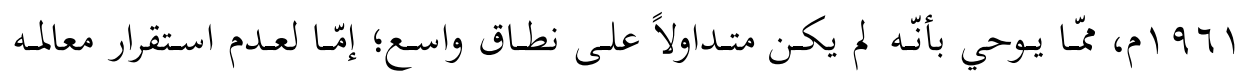

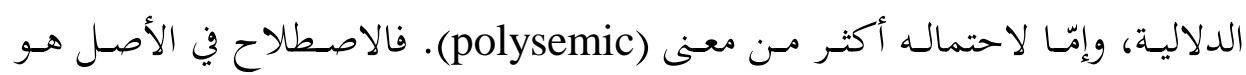

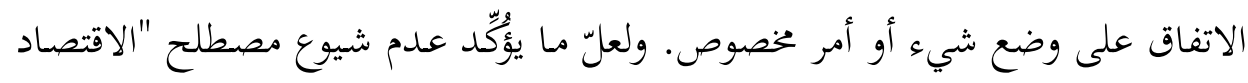

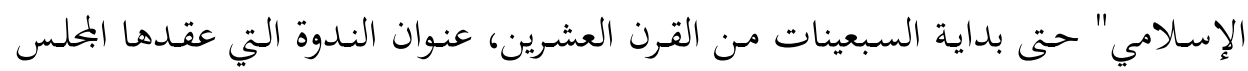

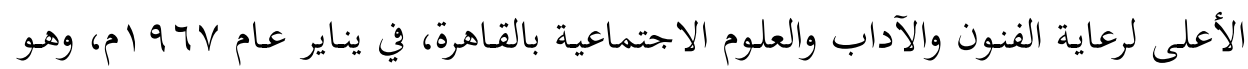

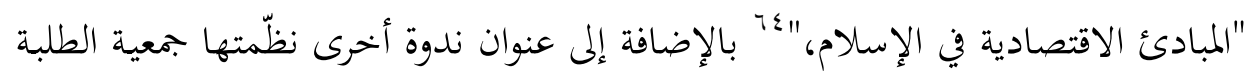

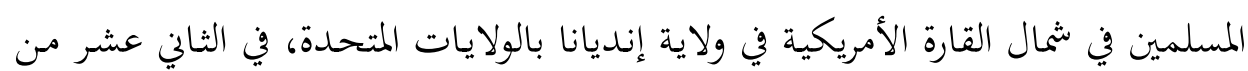

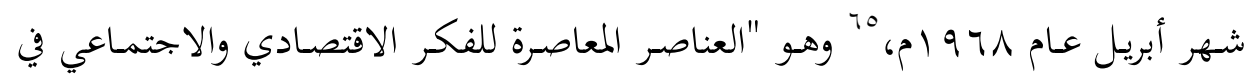

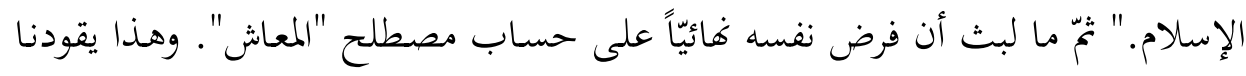

${ }^{61}$ Système d'économie islamique.

${ }^{62}$ Hamidullah, Muhammad. La politique étrangère du Pakistan et son arrière-plan, Politique étrangère, 16(2), 1951, p.139.

${ }^{63}$ Kuran, Timur. Islam and Mammon: The Economic Predicaments of Islamism, Princeton: Princeton University Press, 2004, p.84-85.

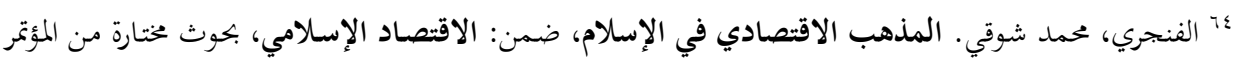

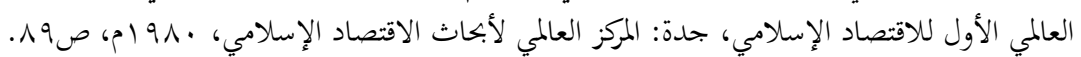

${ }^{65}$ Contemporary aspects of economic and social thinking in Islam, Conference of the Muslim Student's Association of the United States and Canada, April 12, 1968. 
إلى تنـاول ترجمـة مصطلحي "المعـاث" و"الاقتصـاد"، مع الإشـارة إلى ضـرورة التفريق بـين الترجمة الثقافية والترجمة الأيديولوجية.

\section{رابعاً: بين الترجمة الثقافية والترجمة الأيديولوجية؟7}

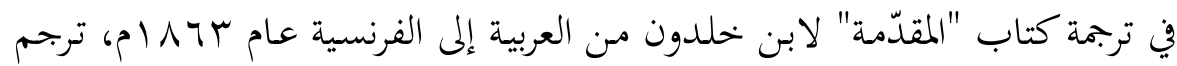
وليام دي سلان لفظة "المعاش" تارة بعبارة moyens de se procurer la (travailler pour أي طرائق الحصول على الرزق، وتارة أُخرى بعبارة (subsistence)

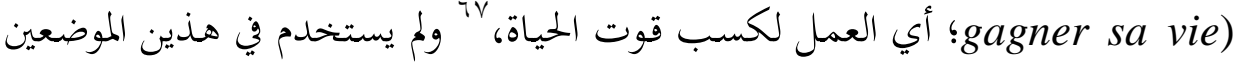
لفظة "اقتصاد." في حين صنّف إيف لاكوست ابن خلدون بأنّه مؤسس علم الاقتصاد

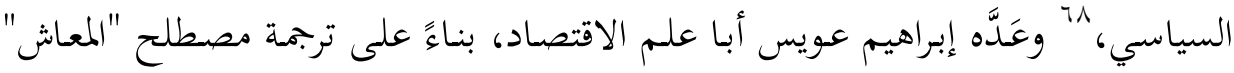
بالاقتصاد.

إنّ وصف ابن خلدون بمؤسس (أو أبي) علم الاقتصاد على هذا المنوال ليس تشريفاً له، بل منقصة له؛ لأنّ هذا الوصف يهصره في قالب المنظومة الفكرية التقليدية للاقتصاد

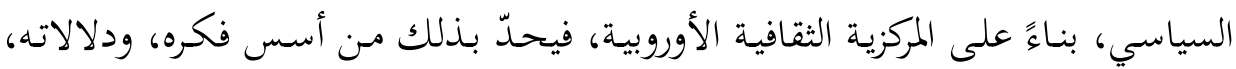

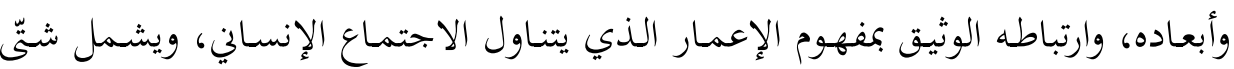

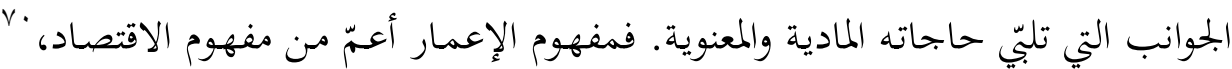

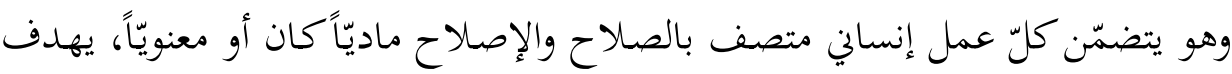

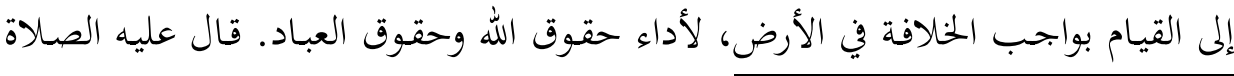

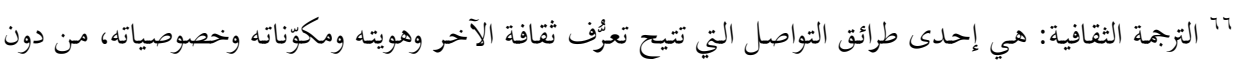

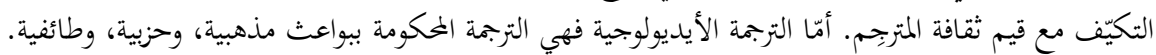

${ }^{67}$ Ibn Khaldoun. Les Prolégomènes, traduits en Français et commentés par William Mac Guckin de Slane, troisième partie, Paris: Institut de France, 1863, p.4 et p.448.

${ }^{68}$ Lacoste, Yves. Maghreb, peuples et civilisations, Paris: La Découverte, 1995, p.17.

${ }^{69}$ Oweiss, Ibrahim M.. Ibn Khaldun, the Father of Economics, George Nicholas Atiyeh. Arab Civilization: Challenges and Responses. Studies in Honor of Constantine K. Zurayk, State University of New York, 1988, p.112-127.

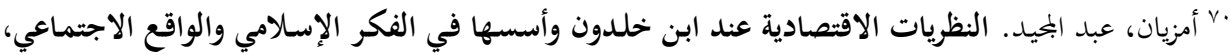

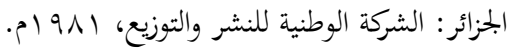




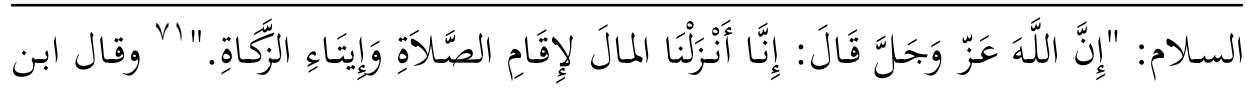

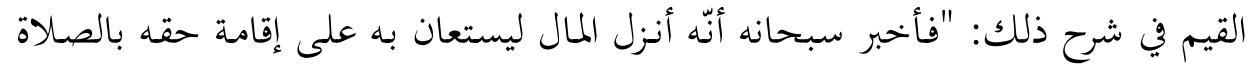

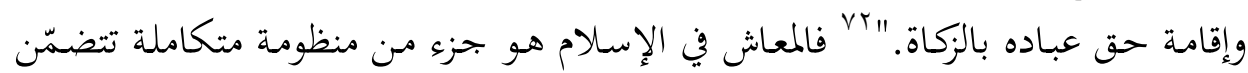

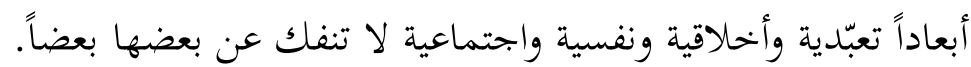
مسن جهـة أخـرى، يميـل بعض البـاحثين مـن النـاطقين بالأرديـة إلى ترجمـة مصسطلح

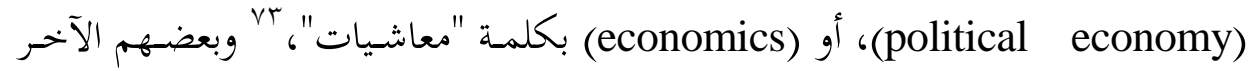

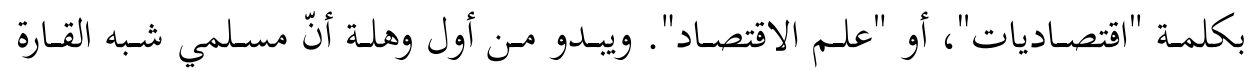

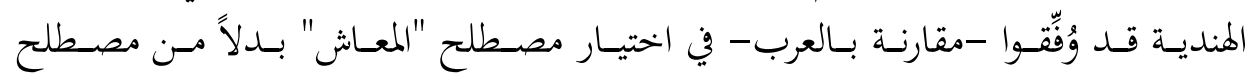

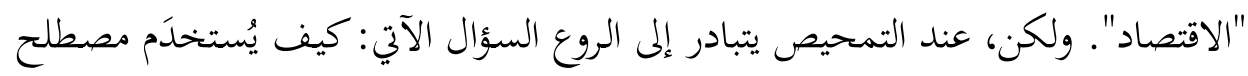

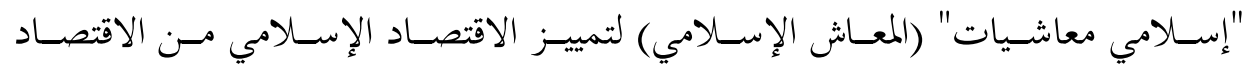

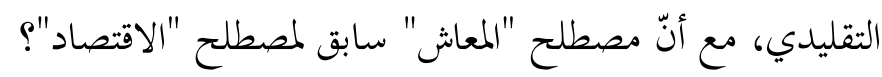

فبناءً على طبيعة التأثنّر، يُفترَضَ أن يتأثَّ اللاحق بالسابق وليس العكس. والظاهر أنّ

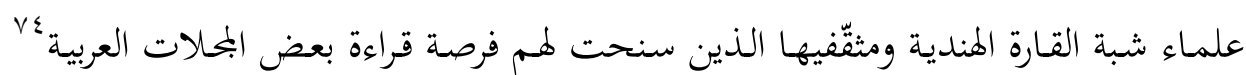

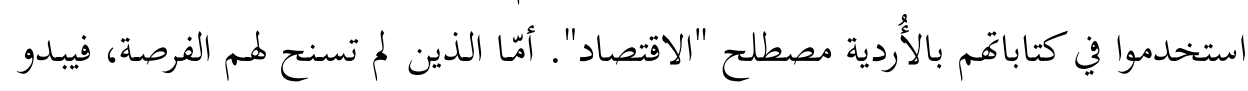

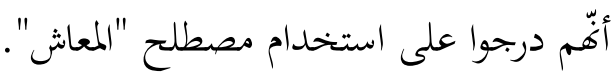

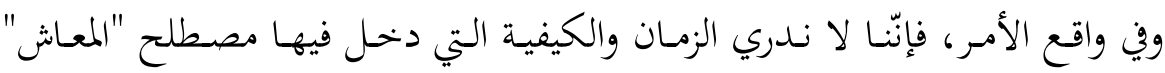

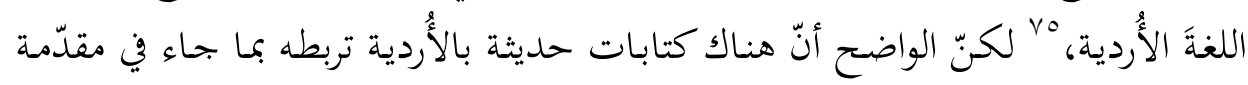

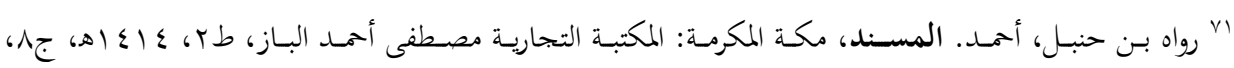

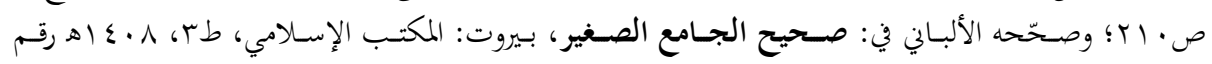
$.1 \vee \wedge 1$

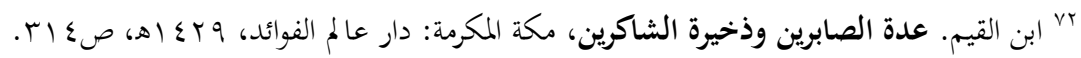

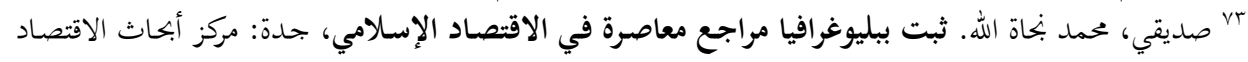

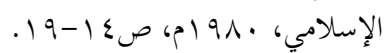

Siddiqi, Muhammad Nejatullah. Muslim Economic Thinking: A Survey of Contemporary Literature, Leicester: The Islamic Foundation and Jeddah: International Center for Research in Islamic Economics, 1981, pp. 83-87. ع v لا سيّما بحلة المنار التي كانت ذائعة الصيت في مختلف أنحاء العالم الإسلامي.

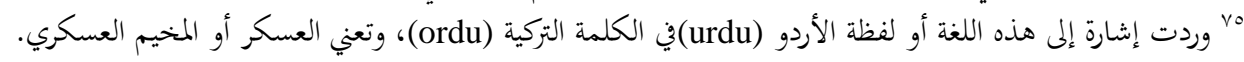

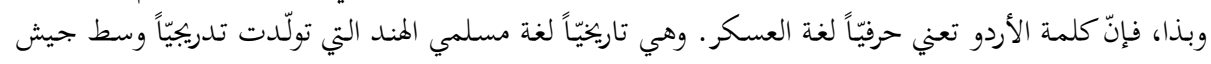




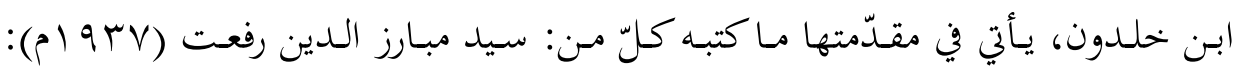

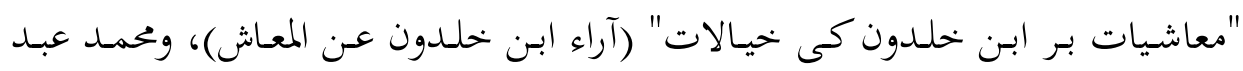

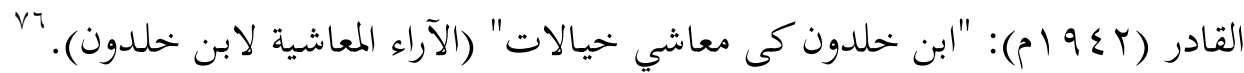

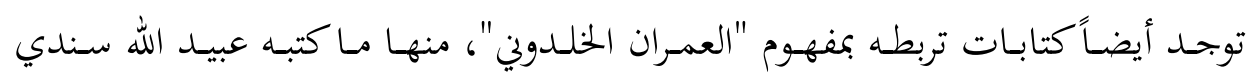

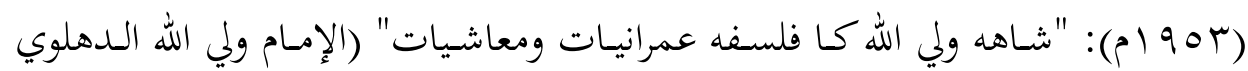
وفلسفته في العمران والمعاش).

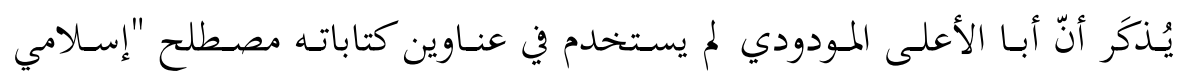

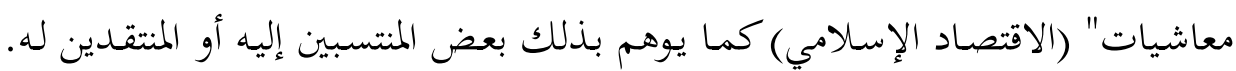

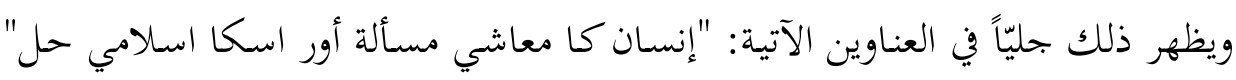

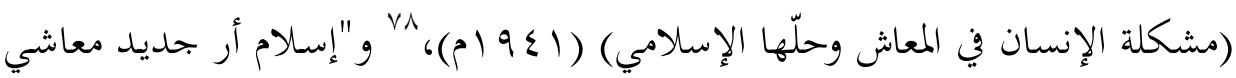

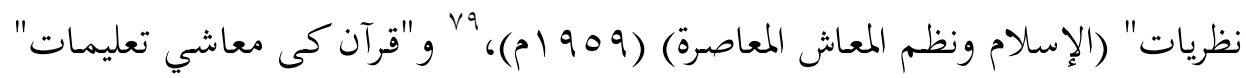

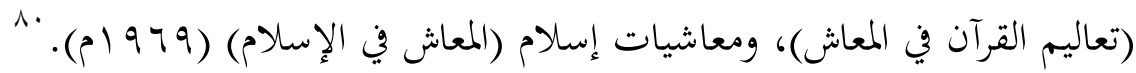
وبهـا حصل توافق في النتيجة بين بعض الأوروبيين والمسلمين، فترجم الأوروبيون

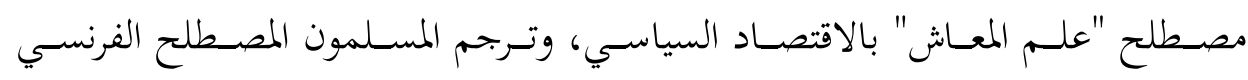
(économie politique)

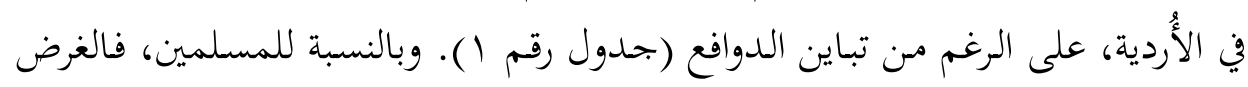

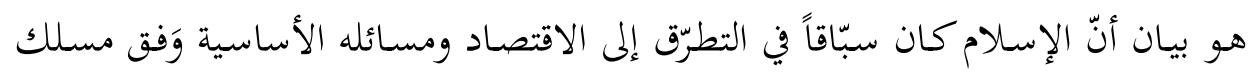

المسلمين والأسواق الشعبية في عهد الخلافة الإسلامية. لذا، فقد بُنيت أساساً على اللغة المحلية، واللغة الفارسية، واللغة العربية، وبعض الأكواف الثعلة في التركية.

${ }^{76}$ Siddiqi, op. cit, p. 122.

${ }^{77}$ Siddiqi, op. cit, p. 124.

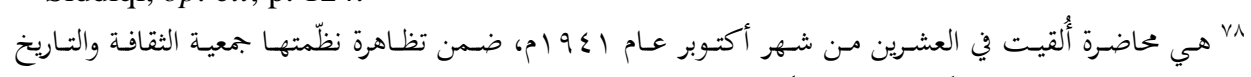
الإسلامي في جامعة عليكره بالهند، نقاًاً عن المرجع الآتي:

Bosworth, C.E., van Donzel, E., Heinrichs, and W.P. \& Pellat, C. Encyclopédie de l'Islam, Leiden et Paris: E.J. Brill et G. P. Maisonneuve Larose S.A., 1989, fascicule 11, p.864.

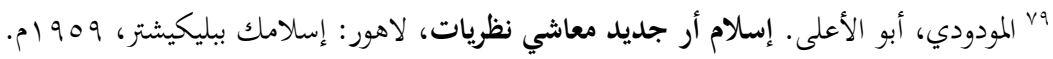

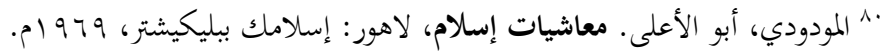


قائم على ردّ الفعل لإيجاد مقابل إسلامي لما هو سائد عند الأوروبيين، وهذا مـ الظواهر

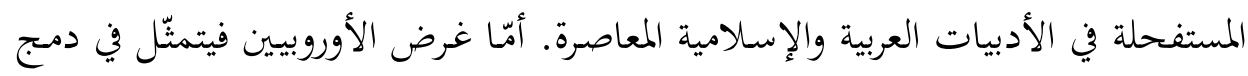

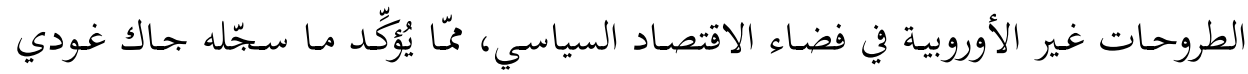
بخصوص ميل الأوروبيين إلى كتابة التاريخ من منظور مركزي، وفرض (Jack Goody)

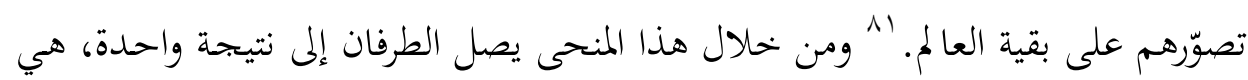

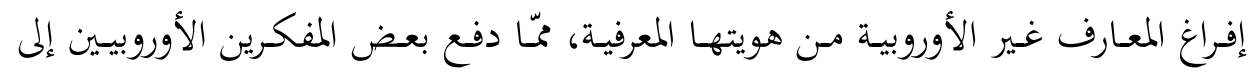

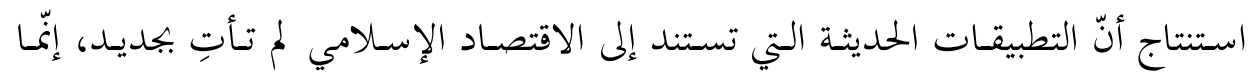

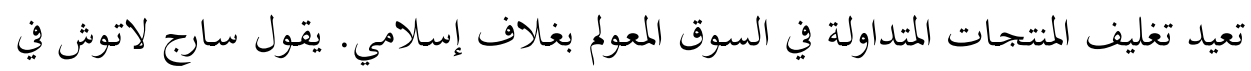
كتابه (تغريب العالم): "إن مضمون ما يسمى بالاقتصاد الإسلامي دون أن يكون فارغاً

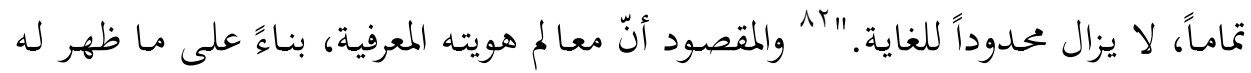

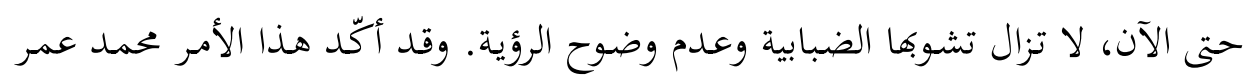

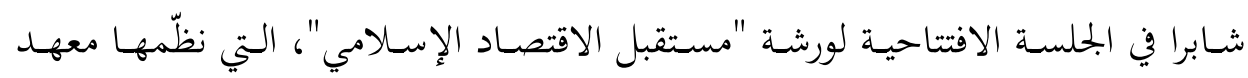

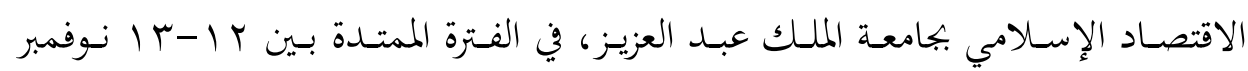
r ا • ب م. وهذا يجرنا إلى تناول إيجابيات تسمية الاقتصاد الإسلامي وسلبياها. جدول رقم (1): مفردات المال، والرزق، والكسب، والمعيشة، والاقتصاد

\begin{tabular}{|c|c|c|c|}
\hline العربية & الأُردية & الإنجليزية & الفرنسية \\
\hline مال & مال & $\begin{array}{l}\text { money, asset, } \\
\text { good, fortune, } \\
\text { wealth }\end{array}$ & $\begin{array}{l}\text { argent, avoir, } \\
\text { bien, fortune, } \\
\text { richesse }\end{array}$ \\
\hline رزق & رزق & $\begin{array}{l}\text { sustenance, } \\
\text { subsistence, } \\
\text { livelihood }\end{array}$ & $\begin{array}{l}\text { subsistance, ce } \\
\text { dont on bénéficie }\end{array}$ \\
\hline
\end{tabular}

ایغ غودي، جاك. سرقة التاريخ، ترجمة: محمد محمود توبة لكتاب: (The Theft of History)، الرياض: مكتبة

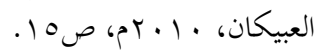

${ }^{82}$ Latouche, Serge. L'occidentalisation du monde, Paris: La Découverte, 2005, p.18. 


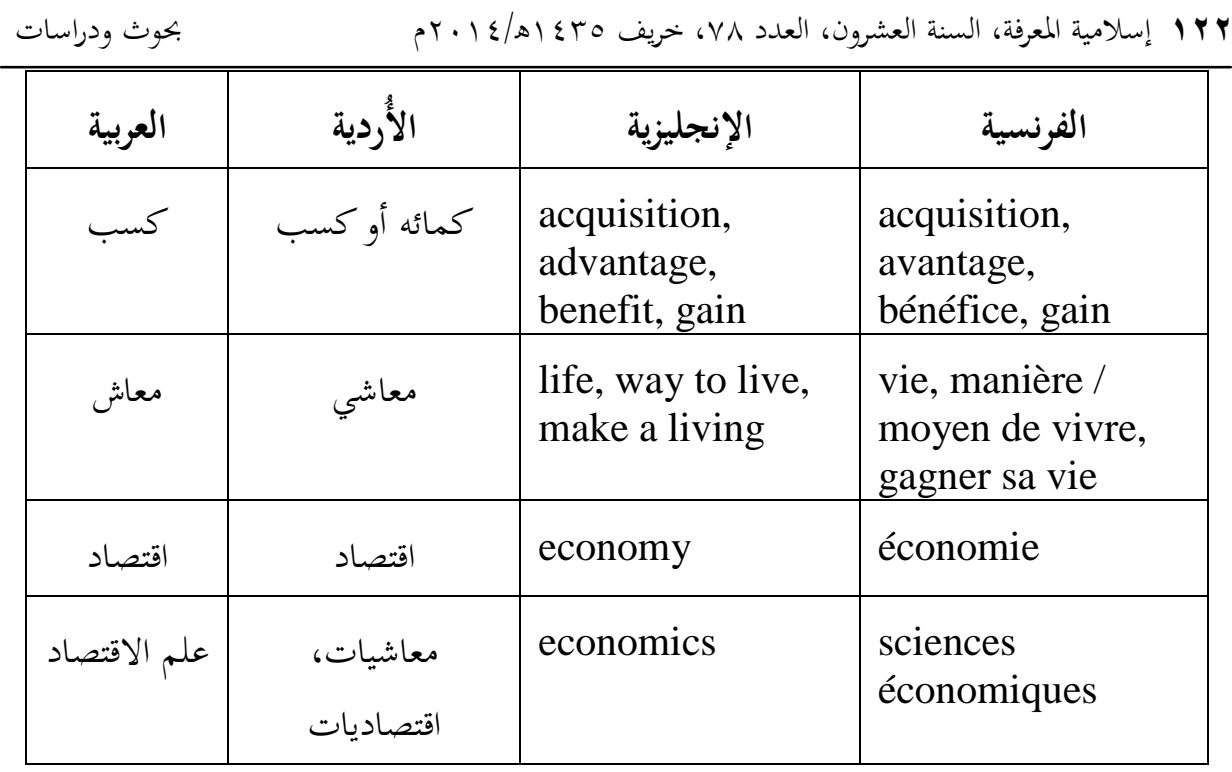

\section{خامساً: إيجابيات مصطلح "الاقتصاد الإسلامي" وسلبياته}

لكله شيء مصلحة ومفسدة، فلا توجد مصلحة بحتة، ولا مفسدة بكتة. وهذا ينطبق أيضاً على الألفاظ والمصطلحات؛ حتى تلك التي تتضمّن صفة "الإسلامي" "، أو تستمد

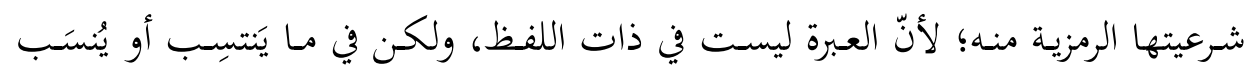

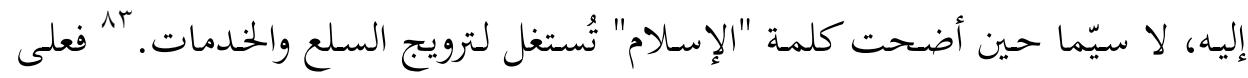
الرغم مسن شسيوعها النسبي، تبقى تسـمية "الاقتصـاد الإسـلامي" اجتهاداً دلاليّاً معاصـراً مرتبطـاً بظـروف معيّنـة، لـه إيجابياتـه وسـلبياته. ووفي حـال بتهـاوزت سـلبيات اسـتخدام

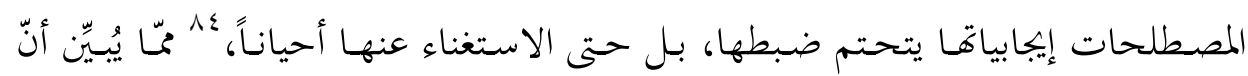

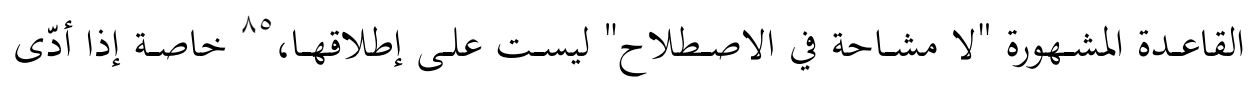

${ }^{83}$ Haenni, Patrick. L'Islam de marché, Paris: Seuil, 2005.

ع^ يُستغنى عن المصطلحات في العلوم لسببين؛ يتمثّل أولاهما في أنّ سلبيات استخدام المصطلح تفوق كثيراً إيجابياته.

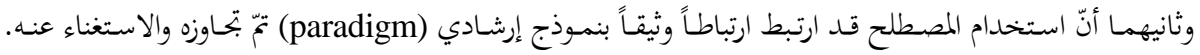

- Tricot, André. Peut-on et doit-on se passer du concept d'intelligence?, La nouvelle revue de l'AIS, n6, 2ème trimestre, 1999, p.6.

ه1 ابن موسى، محمـد الثناني بـن عمر . "التقييـد والإيضـاح لقـولهم (لا مشـاحة في الاصطلاح)"، مجلـة الحكمـة،

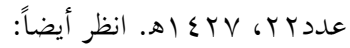


ذلك إلى تنزيل كلام فقهاء السلف وتفسير معاني عباراهم وَفق مصطلحات حادثة، أو

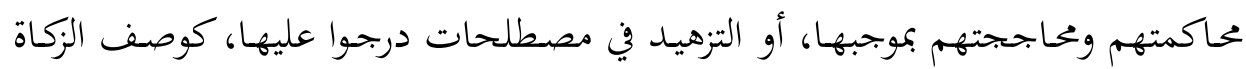

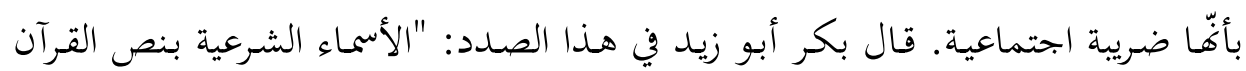

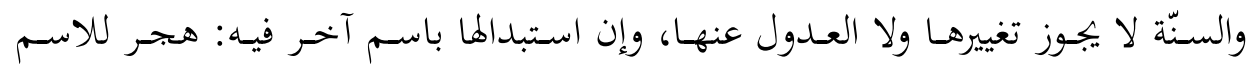

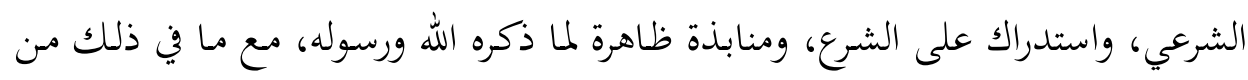

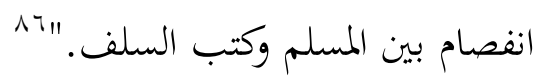
وفي ما يأتي بعض من إيجابيات هذه التسمية: - - إعادة إحياء التراث الإسلامي في حقل المعاش، والتأكيد على أنّ الإسلام دين

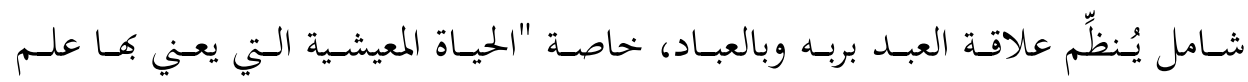
الاقتصاد.

- - مإبراز مدرسـة جديـدة ذات مبـادئ متميِّزة لم يعـد بالإمكان بتاهلها حتى مـن الأوروبيين. وفي ذلك، يقول "أندراي زوبوف" أستاذ العلاقات الدولية بجامعة موسكو :

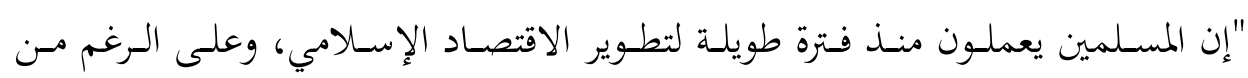

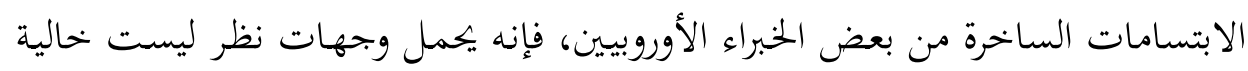

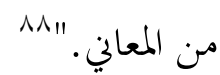

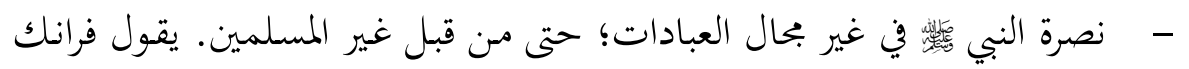

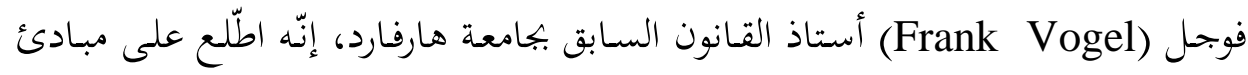

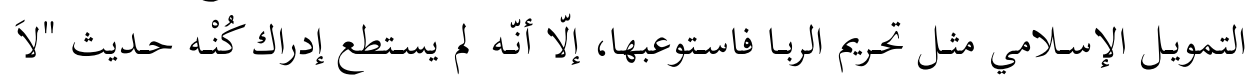

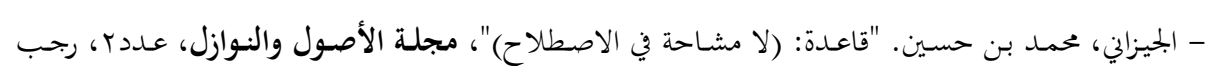
.

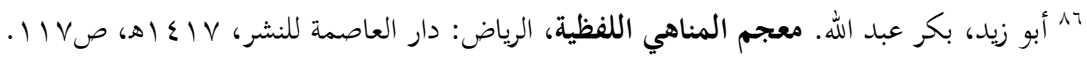

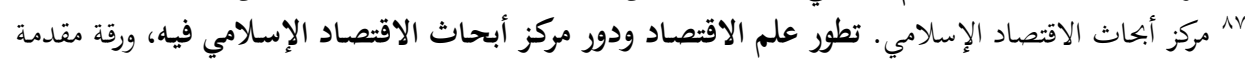

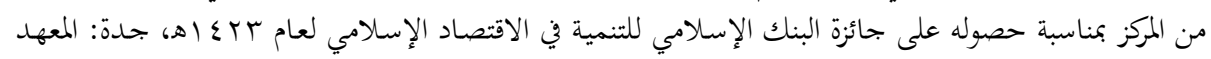

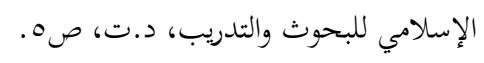

${ }^{88}$ Zoubov, Andrei. La foi et l'économie comme problème pour le XXI ${ }^{\mathrm{e}}$ siècle, in Calvez, Jean-Yves \& Zoubov, Andrei, Eglise et économie: voix orthodoxes russes, voix catholiques romaines, Paris: Cerf, 2006, p.197. 


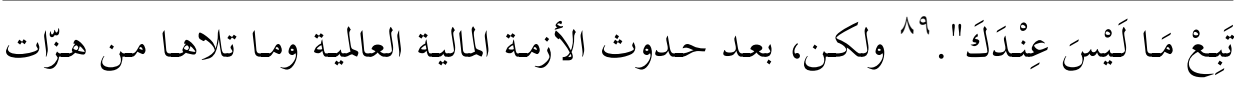

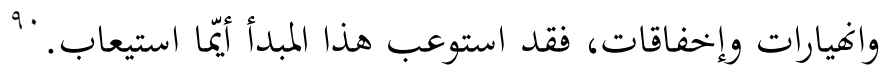
أمّا أبرز سلبياتما فتتمثّل في ما يأتي:

- - حصـر التصوّر والتفكير في ثنائيـة "الاقتصـاد/ الفقـه". وعلى الرغم مـن الأهيـة الكبرى للفقهـ والاقتصـاد بوصفهما مـن التخصصات العلميـة، فبإنّ السلوك الاقتصـادي يظلّ ظاهرة اجتماعية معقّدة ومتعدّدة الأبعاد، تحتاج إلى تخصصات مختلفة، خاصة علم الاجتماع، وعلم الإنسان، وفلسفة العلوم، وعلم اجتماع المعرفة.

- تصنيف كتابات الاقتصاد الإسلامي للأجيال الأولى بناءً على الخلفية (الحصيلة)

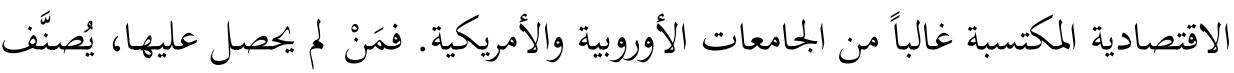
بأنّه يكتب بطريقة تقليدية. - - الإيحاء بوجود كلّية متجانسة اسمها "الاقتصاد الإسلامي" مقابل كلّية متجانسة أُخرى اسمها "الاقتصاد غير الإسـلامي". بو وهـا خطأ منهجي مردّه غيـاب الإحساس بأهمية تاريخ الوقائع الاقتصادية التي عاشها المسلمون في ظروف زمانية ومكانية مختلفة.

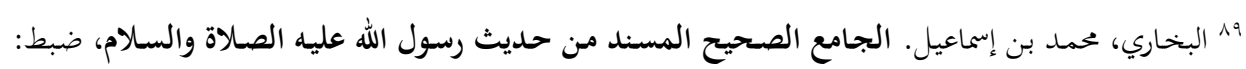

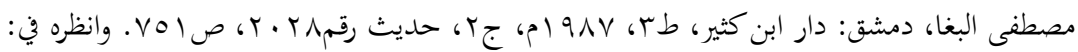

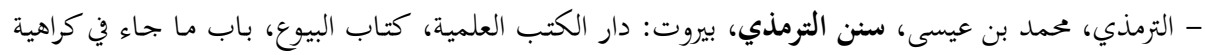

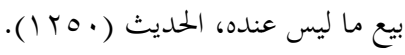

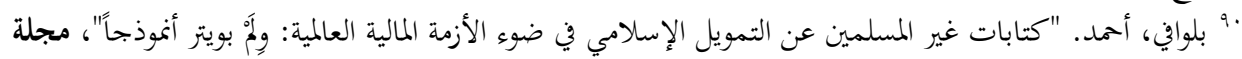

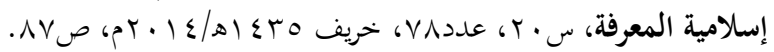

${ }^{91}$ Siddiqi, op. cit, p.2; Islahi, Abdul Azim. Four Generations of Islamic Economists, Journal of King Abdulaziz University: Islamic Economics, Vol. 23 No. 1, 2010, p.165.

$$
\text { r أوضحت بعض الدراسات وجود أشكال متنوعة للرأسمالية. انظر مثلاً: }
$$

Hall, Peter \& Soskice, David. Varieties of Capitalism: The Institutional Foundations of Comparative Advantage, Oxford: Oxford University Press, 2001.

Amable, Bruno. Les cinq capitalismes. Diversité des systèmes économiques et sociaux dans la mondialisation, Paris: Seuil, 2005. 
- استحضار ما هو غير إسلامي بصفة تكاد تكون آلية، خاصة النظامين: الرأسمالي، والاشتراكي. وما زال الجيل الجحديد من الباحثين يُردِد خطاب خمسينات القرن الماضي القائل بأنّ الاقتصاد الإسلامي هو وسط بين الاشتراكية والرأسمالية، وأنّ فيه أفضل ما في النظامين.

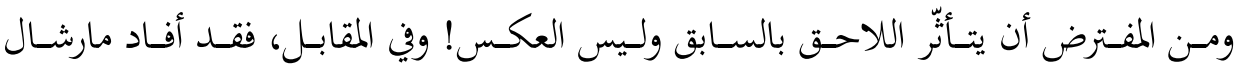

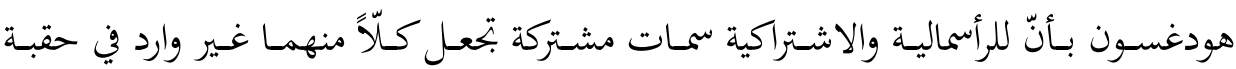
سابقة.

سادسـاً: عـدم استقرار دلالات مصـطلح "الاقتصـاد الإسـلامي" على أسس علميـة متينة

منـذ المـؤتمر العـالمي الأول للاقتصـاد الإسـلامي، انخصـر طـرح البـاحثين في الاقتصـاد

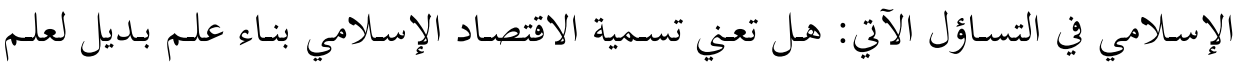

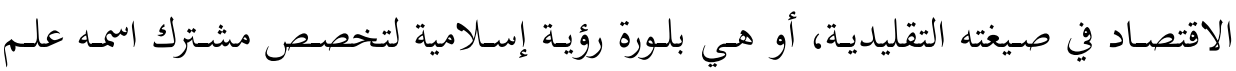

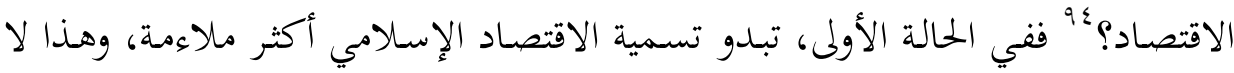

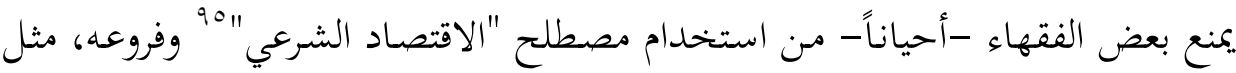

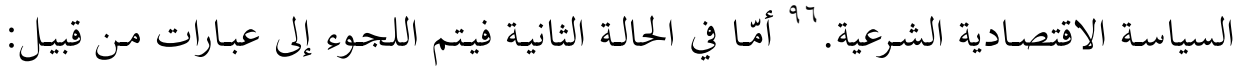

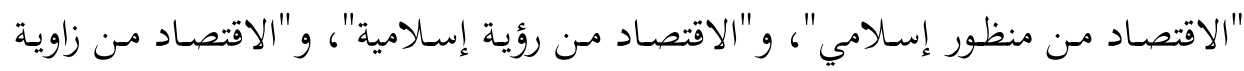

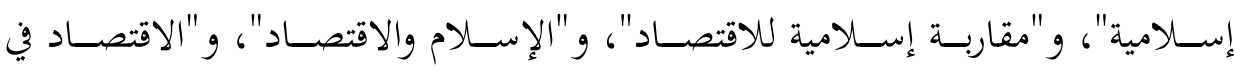

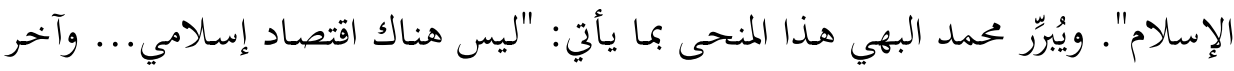

${ }^{93}$ Hodgson, Marshall. L'Islam dans l'histoire mondiale, textes réunis, traduits de l'américain et préfacés par Abdesselam Cheddadi, Paris, Actes Sud / Sindbad, 1998, p.245.

${ }^{94}$ Kahf, Monzer. Definition and Methodology of Islamic economics, Review of Islamic Economics, No. 13, 2003, p.31.

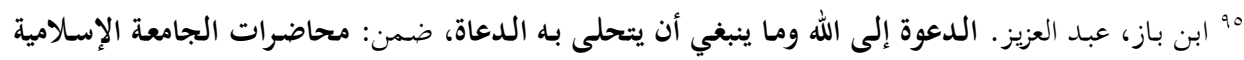

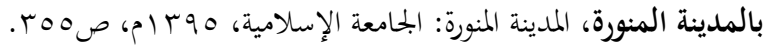

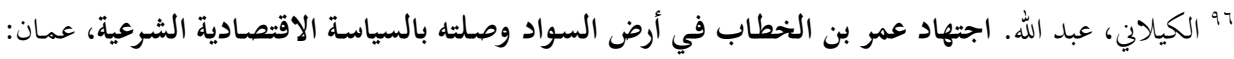

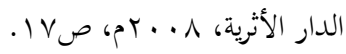


غير إسـامي. وإنما هنـاك نظرة الإسـام إلى الاقتصـاد، ونظـرة غير الإسـام إليـه [...]

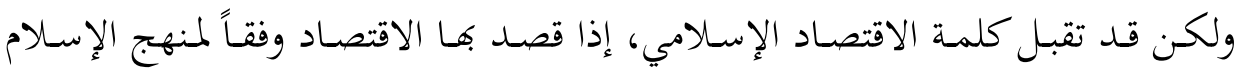

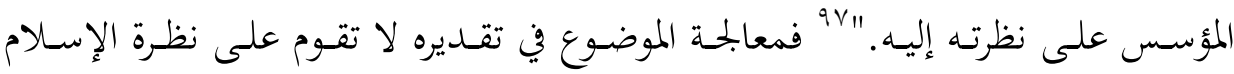

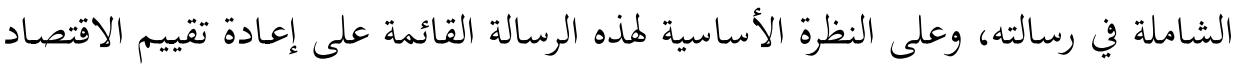

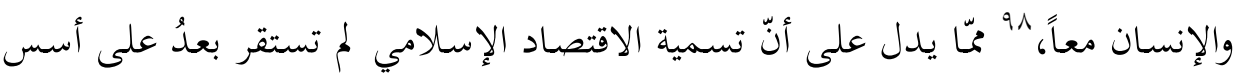

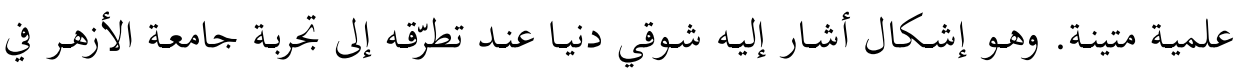

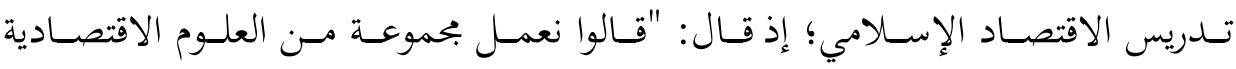

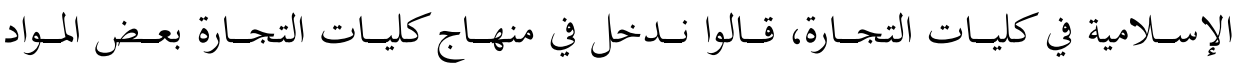

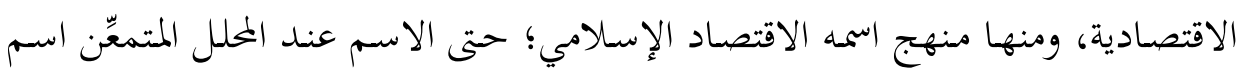

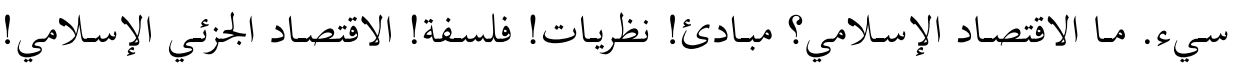

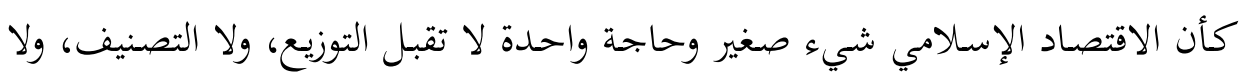

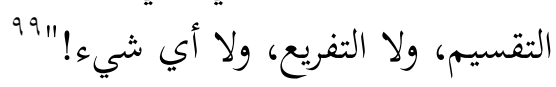

ينبغي التنبيـه هنـا على أنّ كليـة التجـارة في جامعـة الأزهـر لم تسـتحدث في الفـترة

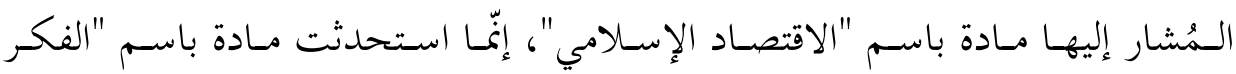

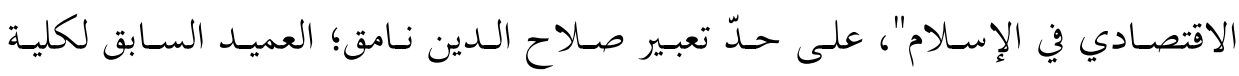

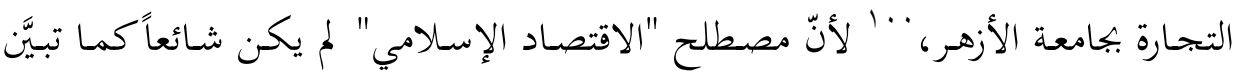

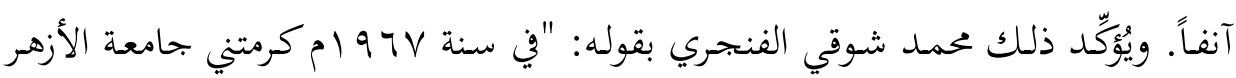

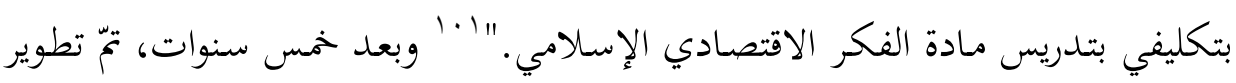

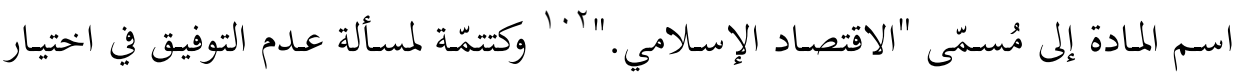

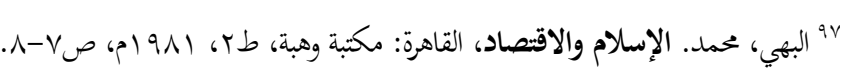

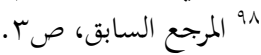

99 دنيا، شوقي. البحث الاقتبادي، صنادي الإسلامي: واقعه وطموحاته، القاهرة: مركز صالح كامل للاقتصاد الإسلامي،

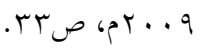

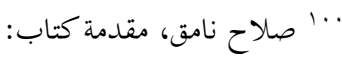

- الفنجري، محمد شوقي. ذاتية السياسة الاقتصادية الإسلامية وأهمية الاقتصاد الإسلامي، القاهرة: مكتبة

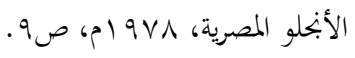

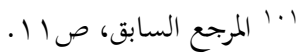

ז.1 المرجع السابق، صابق، صلا ال. 
تسمية الاقتصاد الإسلامي، أشار شوقي دنيا في كتاب آخر: "مع التسليم بأحقية وجود الإد الإديا

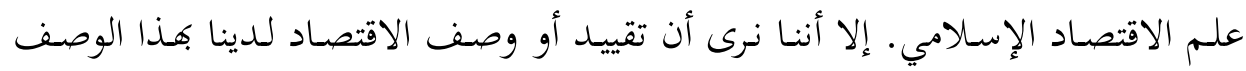

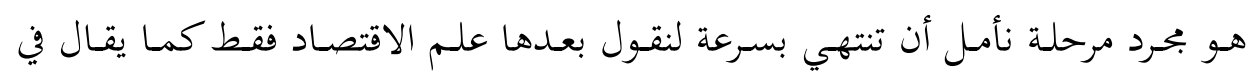

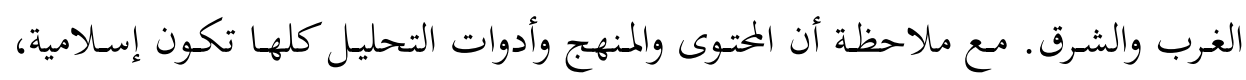

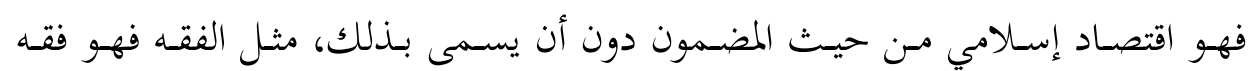

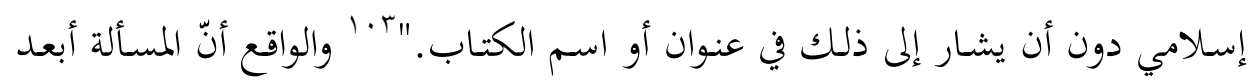

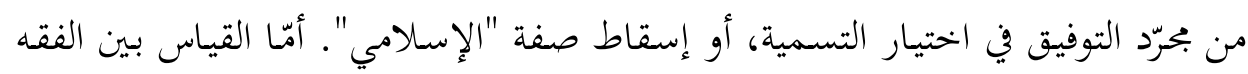

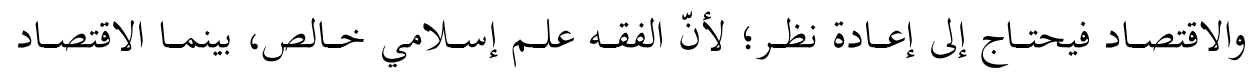
بمفهومه الحديث علم وافد من أوروبا.

\section{خاتمة:}

يخلص البحث إلى أنّ إشكالية البحث في الاقتصاد الإسلامي بدأت أساساً من تبني

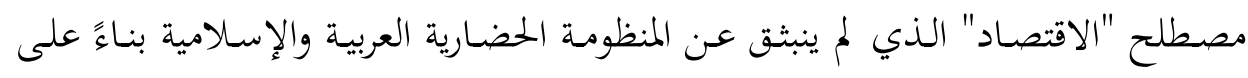

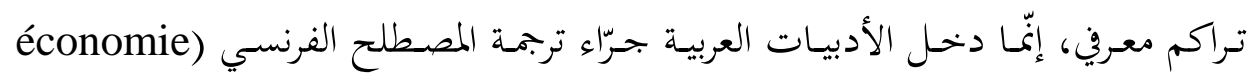

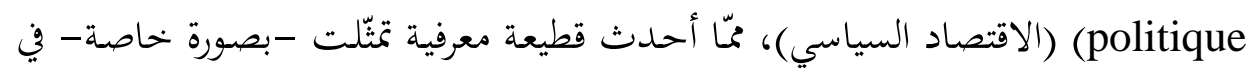
الإعراض عن مصطلح "المعاش" الذي استقر عليه الفقهاء والأدباء في القرون الأخيرة. وبما أنّ المصطلحات ليست حيادية، فمن الصعب بمكان نقل المصطلحات وإعادة

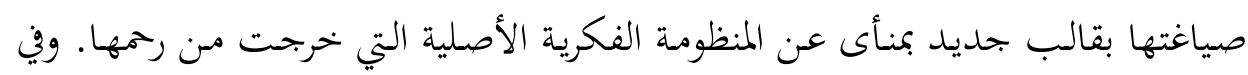

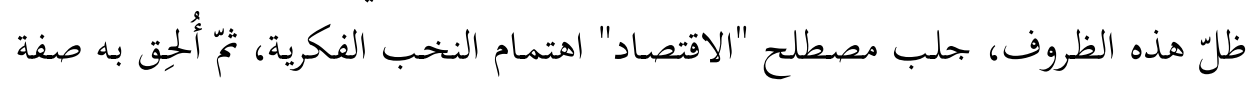
"الإسالامي" بناءً على اجتهاد فردي، ليظهر إلى الوجود مصطلح "الاقتصاد الإسلامي".

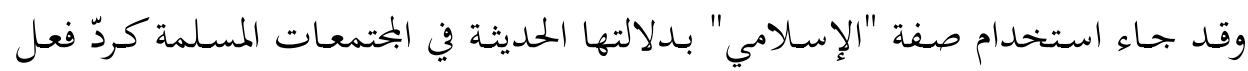

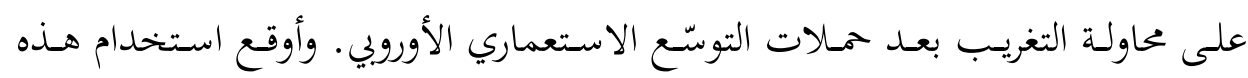

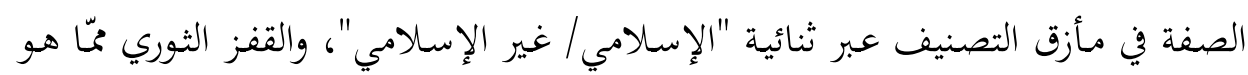




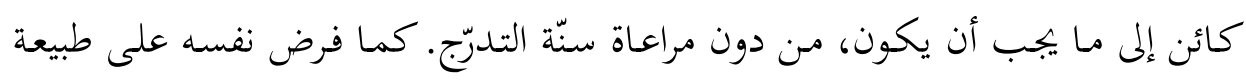

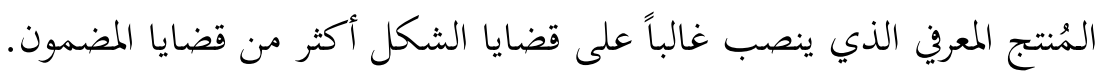

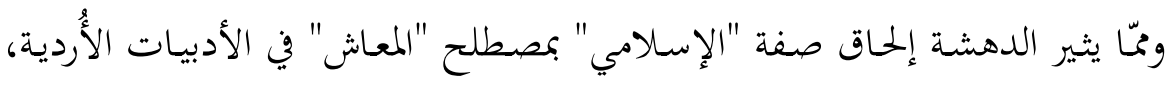

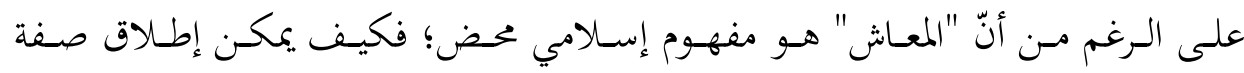

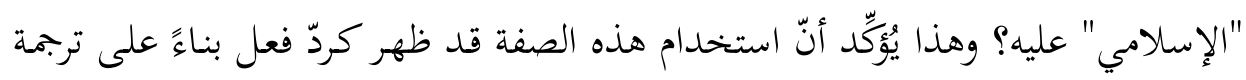

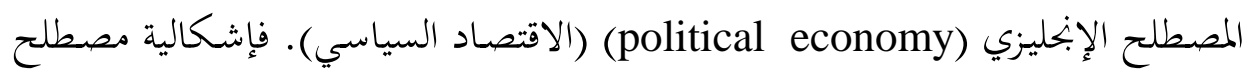

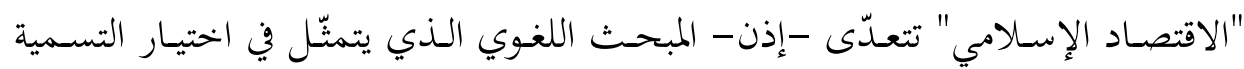

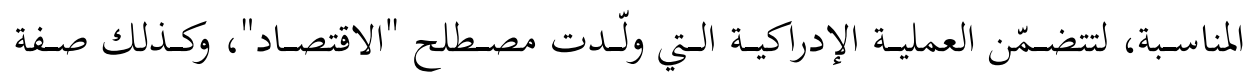

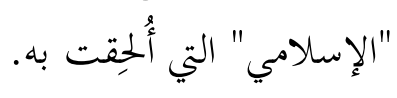

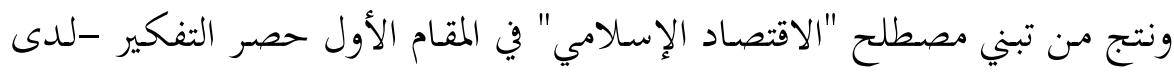

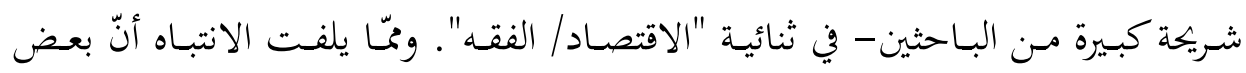

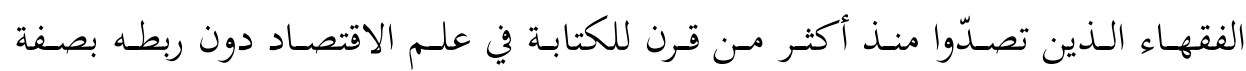

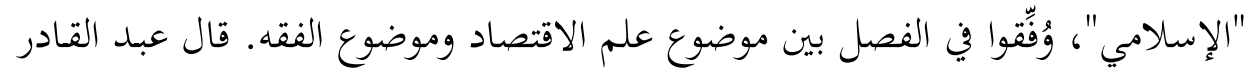

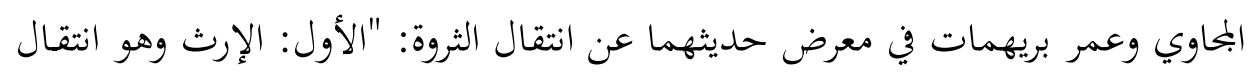

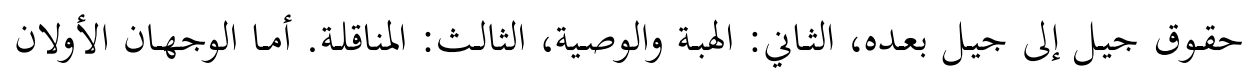

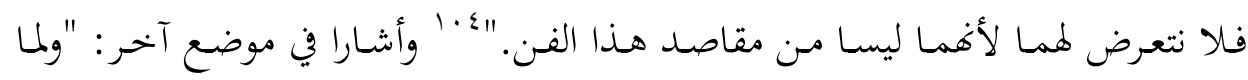

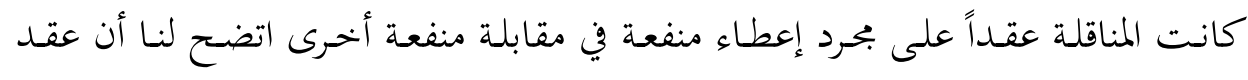

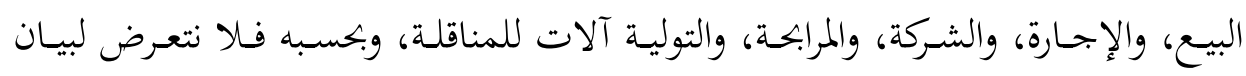

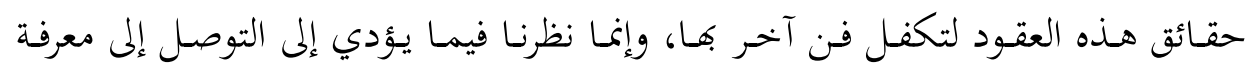

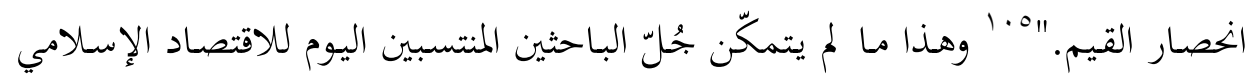

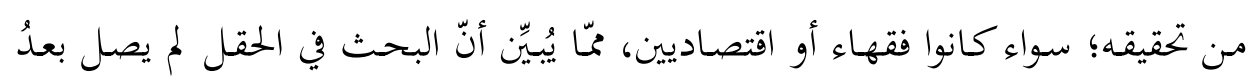

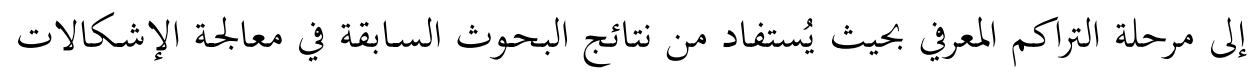
المنهجية وتطوير نتائج لاحقة.

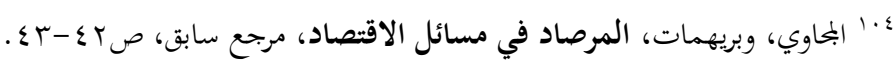

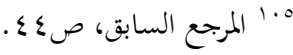


وقد أدّى التمسّك بثنائية "الاقتصاد/ الفقه" إلى الانغلاق على تخصصات أُخرى، لم

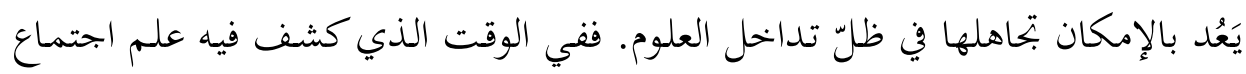

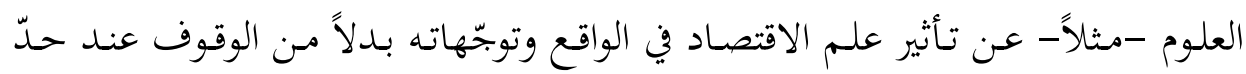

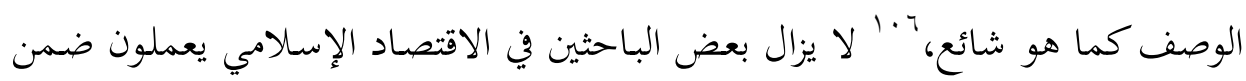

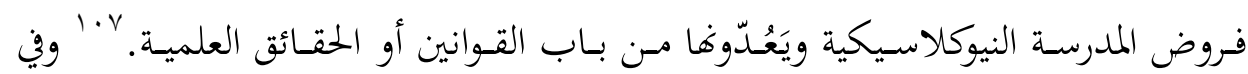

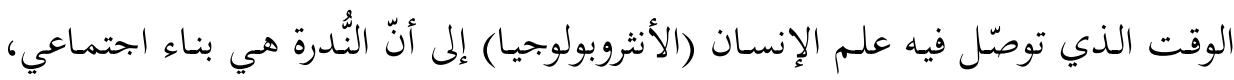

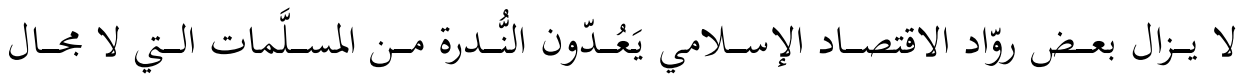

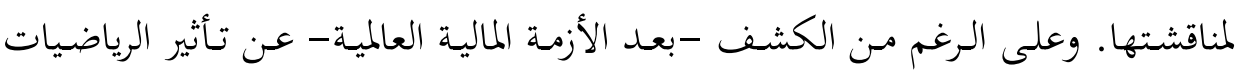

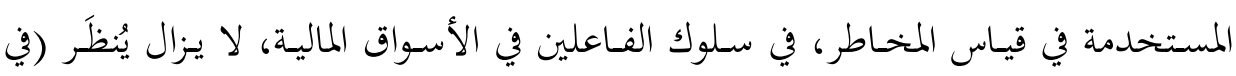

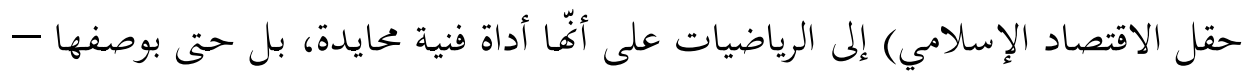
أحياناً- أهم مؤشّر على الرصانة العلمية للمخرجات الرسات البحثية.

وفي الختام، إذا ظهر مصطلح "الاقتصـاد الإسـلامي" كردّ فعل ووُجِد ليبقى، ينبغي بتحـاوز مرحلـة ردّ الفعـل هـــه بالانتقـال إلى مرحلـة الفعـل الـواعي بإيجابيـات المصـطلح

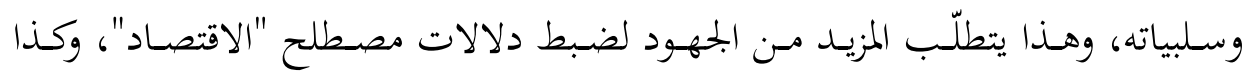

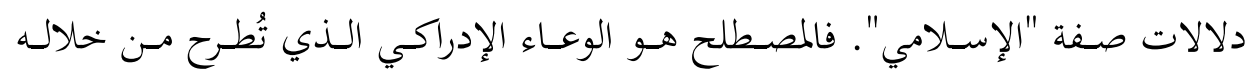

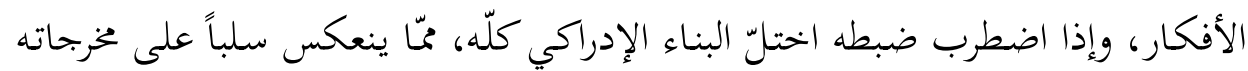
المنهجية والنظرية والتطبيقية.

ينبغي أيضاً إشراك باحثين من تخصصات مختلفة في عملية ضبط دلالات مصطلح "الاقتصـاد الإسـالامي"، لا سـيّما علـم اللسـانيات، وعلـم اجتمـاع العلـوم، والاقتصـاد الإدراكي (cognitive economics)، ثمّ إدراج أهـم الضـوابط التي تمّ الوقوف عليها لتطوير البرامج التعليمية ذات العلاقة.

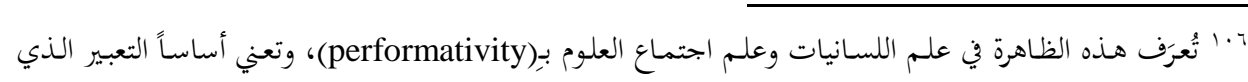

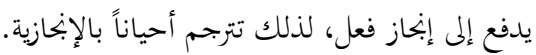

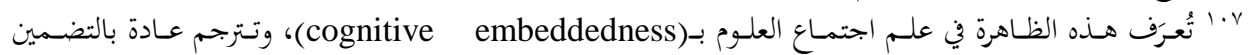
الإدراكي. 


\section{ملحق \\ كتابات تربط عناوينُها الاقتصادَ بالإسالام \\ قبل شيوع مصطلح "الاقتصاد الإسلامي"}

منـذ بدايـة القـرن العشـرين، بـرزت كتابـات بلغـات مختلفــة تربط عناوينهـا الاقتصـاد

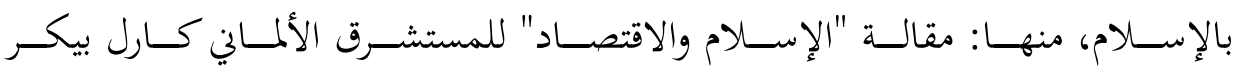

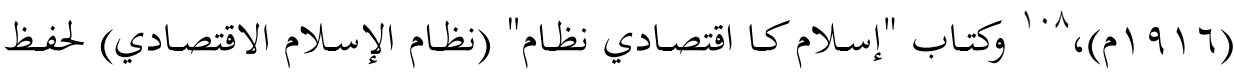

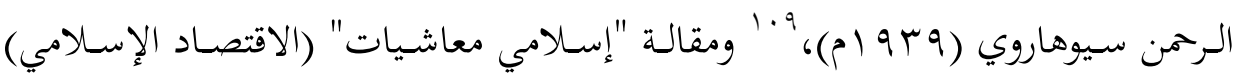

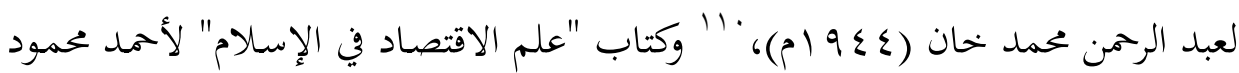

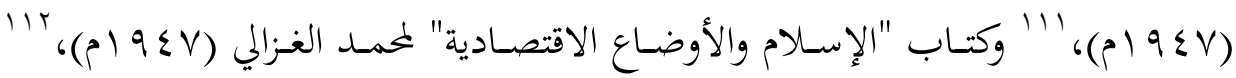
وكتيِّبَ "فتـوى شـرعية في شـئون اقتصـادية" لمخلـوف حســنين مفـتي الـديار المصـرية

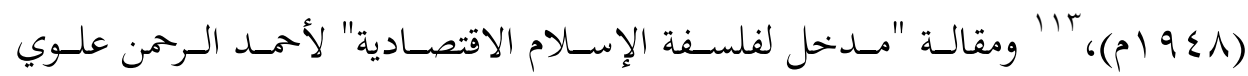

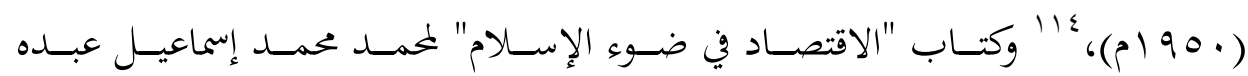

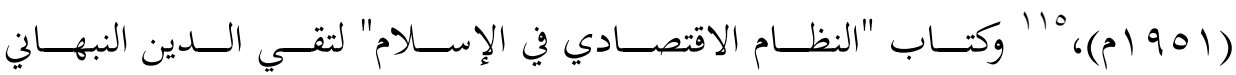

${ }^{108}$ Becker, Carl Heinrich. Islam und Wirtschaft, Archiv fur Wirtschaftsforschung im Orient, I, 1916, p.66-77.

$$
\text { 9. }
$$

- Savharvi, Hafz-ur-Rehman. The Economic System of Islam, Lahore: Idara-e-Islamiat, 2001.

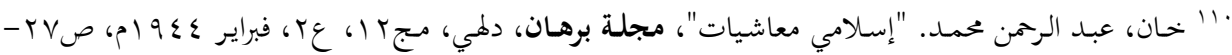

.4

${ }^{111}$ Mahmud, Ahmad. Economics of Islam, a comparative study, Lahore: M. Ashraf, 1947.

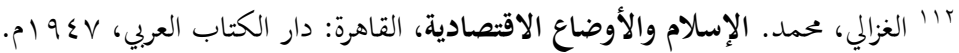

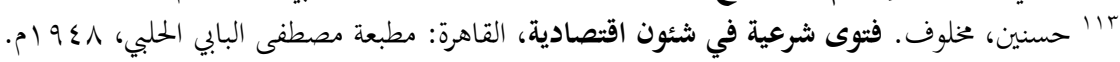

${ }^{114}$ Alavi, Ahmadur Rahman. An Introduction to the Economic Philosophy of Islam, Islamic Literature (Lahore), 2(4), April 1950, p.25-34.

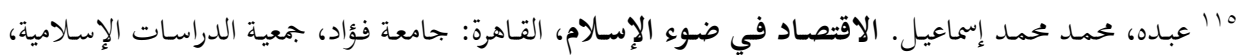

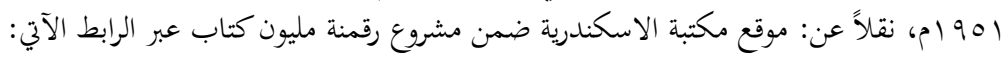

- http://dar.bibalex.org/webpages/mainpage.jsf?BibID=345722 


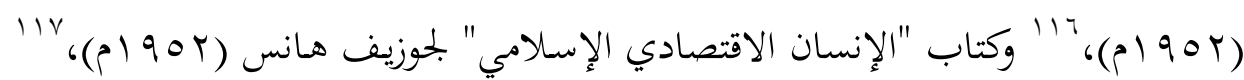
ومقالـة "الإسـالام ونظـام الغـرب الاقتصـادي" لمحمـود بـوزوزو ضـمَّنها عبــارة "النظـام

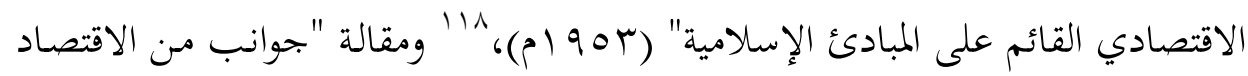

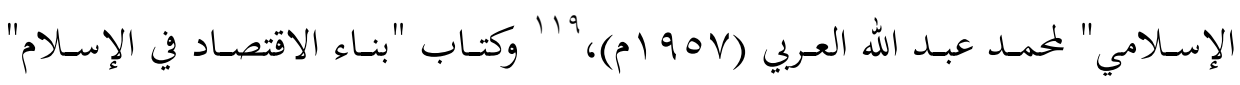

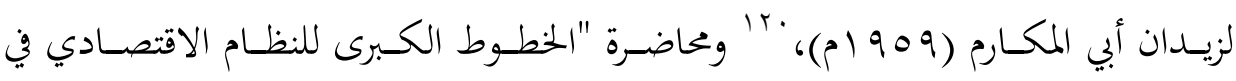

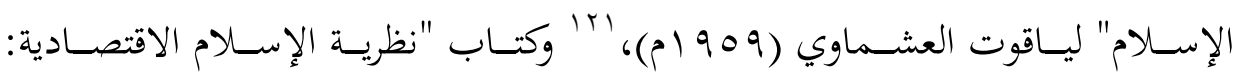

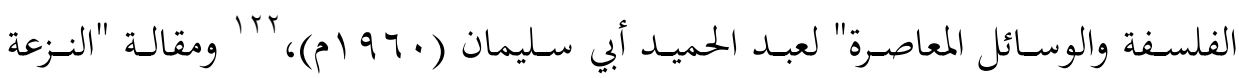

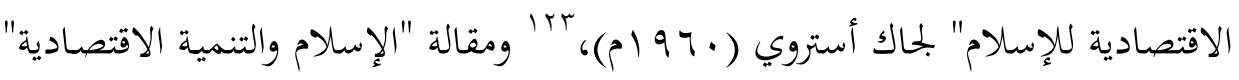

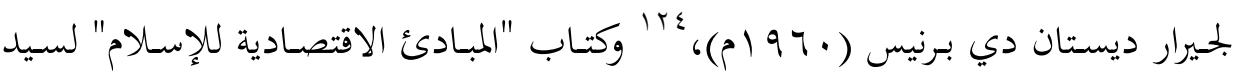

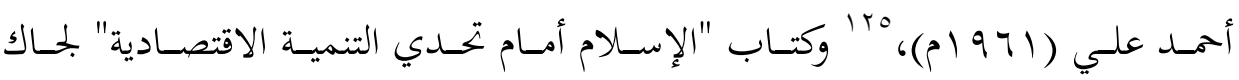

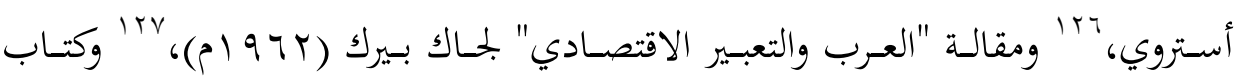
ج11 النبهاني، تقي الدين. النظام الاقتصادي في الإسلام، القدس: منشورات حزب التحرير، 90 ام.

117 Hans, Josef. Homo oeconomicus Islamicus, Wirtschaftswandel und sozialer Aufbruch im Islam, Klagenfurt: J. Leon sen, 1952.

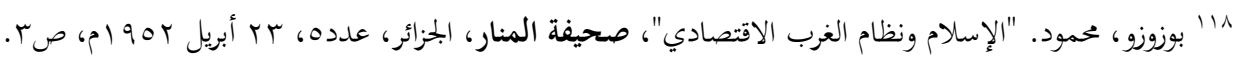
${ }^{119}$ Al-Arabi, Muhammad Abdullah. Some Aspects of Islamic Economics, Islamic Thought (Aligarh), 6(2), March-April, 1957, p.8-19.

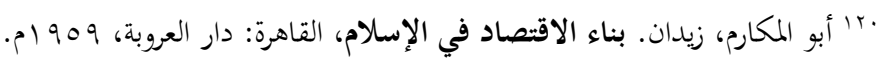

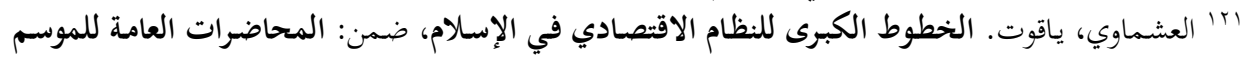

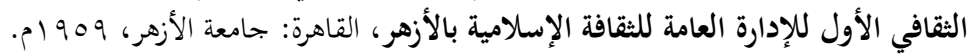

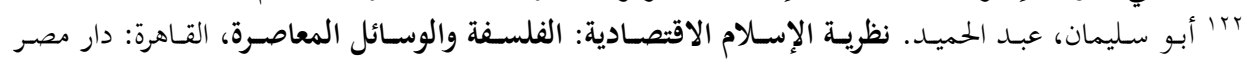

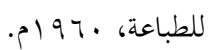

${ }^{123}$ Austruy, Jacques. Vocation économique de l'Islam, Cahiers de l'ISEA, n¹06, octobre 1960, p.151-212.

${ }^{124}$ Bernis, Gérard Destanne de. Islam et développement économique, Cahiers de l'ISEA, n¹06, octobre 1960, p.105-150.

125 Ali, Syed Ahmad. Economic Foundations of Islam. A Social and Economic Study, Calcutta: Orient Longmans, 1961.

126 Austruy, Jacques. L'Islam face au développement économique, Paris: Editions Ouvrières, 1961.

ترجمه إلى العربية نبيل الطويل: جاك أستروي. الإسلام والتنمية الاقتصادية، دمشق: دار الفكر، اب79 ام. 


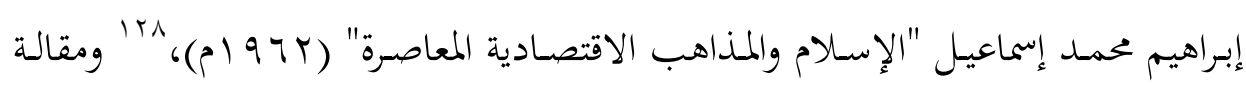

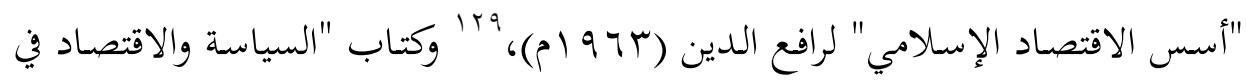

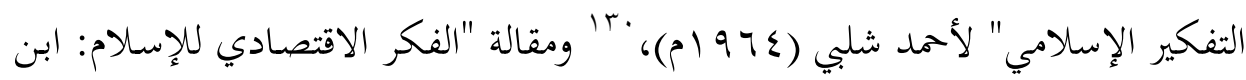

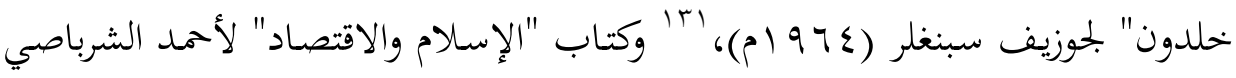

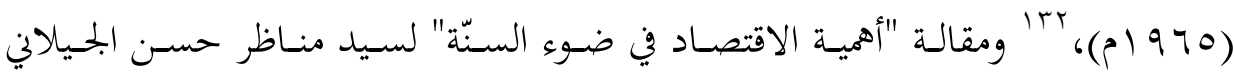

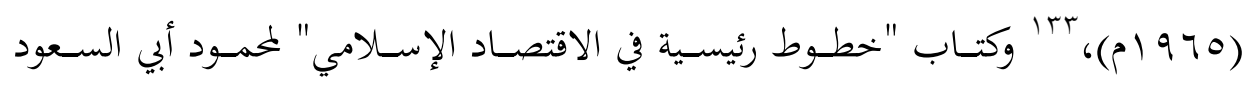

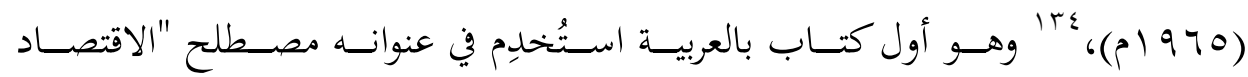

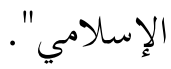

${ }^{127}$ Berque, Jacques. Les Arabes et l'expression économique, Studia Islamica, XVI, 1962, p.95-120.

${ }^{128}$ Ismaïl, Ibrahim Mohammad. L'Islam et les doctrines économiques contemporaines, Le Caire: Conseil supérieur des affaires islamiques, 1962.

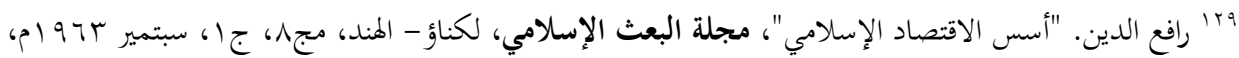

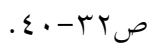

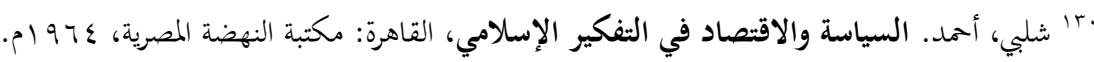

${ }^{131}$ Joseph Spengler. Economic Thought of Islam: Ibn Khaldun, Comparative Studies in Society and History, Vol.6, No.3, April 1964, p.282-306.

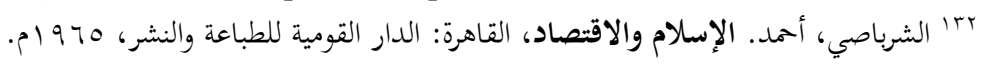

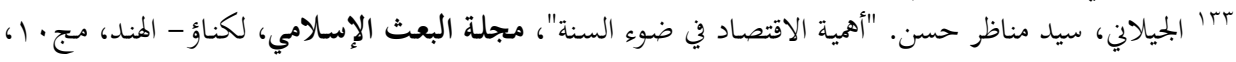

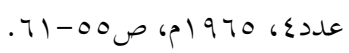

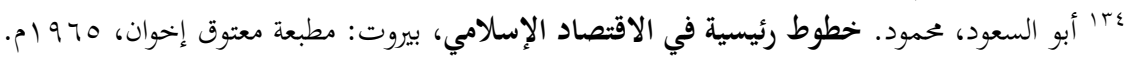

